\title{
'Is there an app for that? An exploratory study into the use of mobile technologies and mLearning within Aotearoa New Zealand's higher education libraries'
}

\author{
by
}

\section{Tracy Marie Maniapoto}

\author{
Submitted to the School of Information Management, \\ Victoria University of Wellington \\ in partial fulfilment of the requirements for the degree of \\ Master of Information Studies
}




\section{ABSTRACT}

\subsection{Research problem}

The objectives of this research study are to explore the extent to which Aotearoa New Zealand's higher education libraries are using mobile technologies for the delivery of its information and research services, and the impact these technologies may have on the professional development needs of higher education library staff.

\subsection{Methodology}

Using a mixed method design approach, two data sets were investigated. First, the web-based library homepages of 29 higher education libraries within Aotearoa New Zealand were examined for their level of conformance to a mobile platform and second, library staff from the 29 higher education libraries were surveyed for their perceptions of, and experiences in, using mobile technology both within a social context and within the workplace.

\subsection{Results}

This research found that while mobile technologies are in use by the majority of higher education libraries to a degree, financial costs and a lack of resources were identified as barriers to providing virtual library users with mobile services that meet both their needs and expectations. In their current state, the web-based library homepages for the majority of libraries are content-heavy and do not conform well to a mobile platform.

This research also found that library staff do not always feel supported in exploring professional development training around mobile technologies and are aware of the impact this may have on providing high level service desk support. In addition, findings suggest library staff are not necessarily aware of new innovations provided by their libraries.

\subsection{Implications}

Library users are likely to experience high levels of dissatisfaction when browsing the library homepage on a mobile web browser due to latency created by content-heavy webpages. Further, mobile services should be fit for purpose to meet the needs and expectations of $21^{\text {st }}$ Century learners. 
For library staff, consideration should be given to developing professional skills when implementing new innovations within the workplace. Communication channels for marketing new innovations should also be clear and distributed to all library staff.

1.5. Keywords/Descriptors

Mobile Technologies, Mobile Apps, Academic Libraries, Tertiary Libraries, Librarians 


\section{ACKNOWLEDGEMENTS}

This research project marks the culmination of 3 years of post-graduate study. As such, there are a number of individuals to acknowledge for their contribution to my higher education learning:

To all who participated in this research - thank you for sharing your time with me so generously. Without you, this project would not have been possible.

To Dr. Brenda Chawner - I extend my eternal gratitude to you for your continued support throughout my time with Victoria University of Wellington. As my supervisor for this research project, your encouragement, patience, understanding and perseverance is valued and sincerely appreciated.

To Dr. Philip Calvert, Alastair Smith, Dr. Dan Dorner, Lynley Stone, Dr. Chern-Li Liew, Dr. Sydney Shep, Dr. Spencer Lilley and Dr. Michael Stephens - it has been a pleasure to share this journey with you and I thank you for the knowledge and experiences you have given me.

To the library staff at Victoria University of Wellington - thank you for your support over the years.

To Margaret (UCOL Palmerston North) and Dawn (Massey University) thank you for satisfying my requests for books, often at short notice.

To the Tuwharetoa Māori Land Trust Board, the East Taupō Lands Trust Charitable Trust and the ExVietnam Services Association Incorporated (EVSA), I am forever grateful for the support you have provided over the past 3 years. I know Dad will be smiling down at me.

To Te Rōpū Whakahau and LIANZA - I am honoured and priviledged to have received your support over the years and look forward to my continued associations with you.

To my Massey University Library colleagues, Tim, Lucy and Julia, thank you for sharing your knowledge, skills and expertise so freely over the past 2 years.

To my Ngā Manu Ka Rere colleagues, Sheeanda, Bruce, Riki-Lee and Moana, thank you for your ongoing support and for providing me with the sustenance I needed. 
To Sarah, thank you for sharing this journey with me from the very beginning. It is such a priviledge to have met you in Wellington at Orientation. Your words always provided me with the inspiration to keep going, particularly when life's challenges crossed my path.

To Troy, thank you e hoa for sharing your experiences with me. As always, your pearls of wisdom were perfectly timed.

To my whānau I extend my deepest aroha:

- $\quad$ Dad-I did it! Miss you heaps.

- Mum - thank you for helping me over the past 3 years with babysitting, running around, and the many other things that only a Mum would do.

- Nathan and Justine - thank you for letting me take over your dining table with my laptop and books, and for not getting grumpy when I used up all of your internet.

- Raven - thank you for giving me time to study when I know you would rather I spent that time with you. Your journey into higher education in a few years time was the inspiration for this research project.

- Rukuwai - thank you for coming into my life; I feel honoured to have you join me along the way.

Tracy Marie Maniapoto

November 2013 


\section{TABLE OF CONTENTS}

$\begin{array}{ll}\text { 1. AbStract } & 2\end{array}$

1.1. Research problem $\quad 2$

1.2. Methodology 2

1.3. Results 2

1.4. Implications 2

1.5. Keywords/Descriptors 3

2. ACKNOWLEDGEMENTS 4

3. TABLE OF CONTENTS $\quad 6$

$\begin{array}{lr}\text { 4. TABLE OF FIGURES } & 8\end{array}$

5. Problem Statement $\quad 10$

5.1. Rationale for the Study $\quad 10$

5.2. Research Objectives $\quad 11$

5.3. Research Questions $\quad 11$

5.4. Theoretical Framework 11

5.5. Definition of Terms 12

5.6. Delimitations / Limitations 13

6. REVIEW OF THE LITERATURE

6.1. Pedagogy of the $21^{\text {st }}$ Century Learner $\quad 15$

6.2. Technology Trends 16

6.3. Mobile Technologies in Use in Education 16

6.4. Library Staff supporting the Ubiquitous Learner $\quad 17$

[6] 
$\begin{array}{lr}\text { 7.1. Research Sample } & 19\end{array}$

7.2. Data Collection $\quad 21$

7.3. Data Analysis $\quad 25$

$\begin{array}{lr}\text { 8. FINDINGS \& DISCUSSION } & 27\end{array}$

8.1. Library Websites 27

8.1.1. Research Question 1: To what extent are Aotearoa New Zealand's higher education libraries currently using mobile technologies for the delivery of its information and research services? $\quad 27$

8.2. Library Staff

8.2.1. Research Question 2: What impact, if any, do mobile technologies have on the professional development needs of higher education librarians?

9. CONCLUSION

10. BIBLIOGRAPHY 


\section{TABLE OF FIgURES}

Figure 1: Mobile devices used to examine Library Homepage rendering ....................................... 23

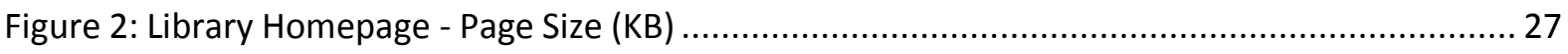

Figure 3: Library Homepage - Page Content Analysis................................................................. 28

Figure 4: Library Homepage - Total Number of Critical Errors....................................................... 29

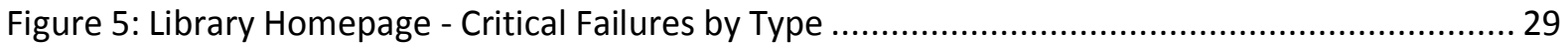

Figure 6: Library Homepage - Total Network Usage (Number of Requests) ..................................... 30

Figure 7: Library Homepage - Network Usage Content Analysis .................................................... 31

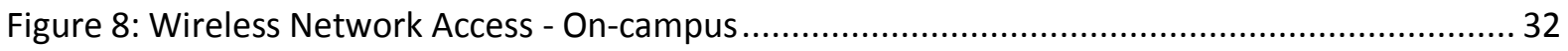

Figure 9: Library Homepage - Vertical and Horizontal Scroll on the iPod Touch ............................... 32

Figure 10: Massey University \& Bay of Plenty Polytechnic Library Homepages (mobile web) -

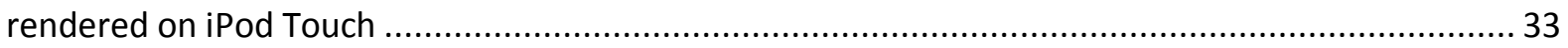

Figure 11: AUT Library Homepage - rendered on iPod Touch ......................................................... 34

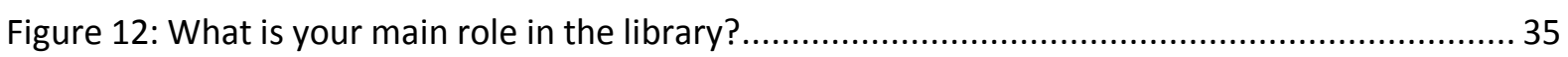

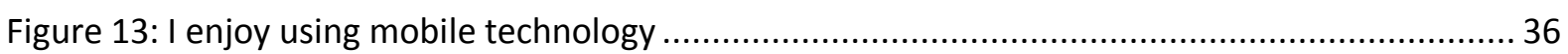

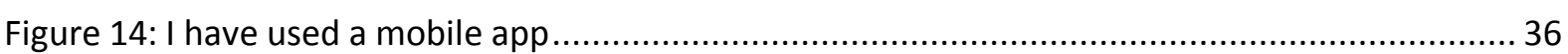

Figure 15: I'm not sure of the difference between a mobile app, and mobile web optimization ....... 37

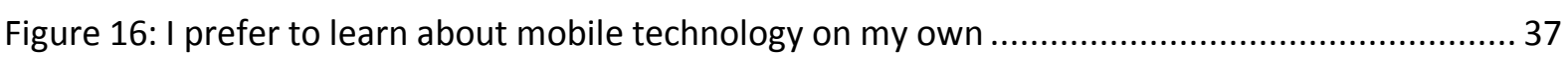

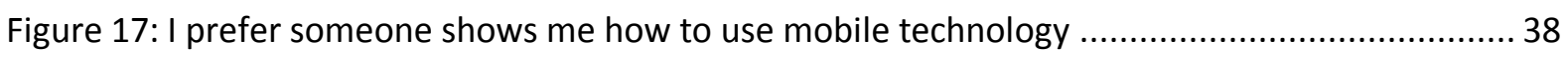

Figure 18: I am more likely to try mobile technology if recommended by a friend or family member 38

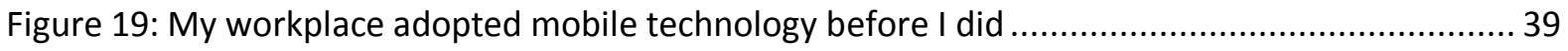

Figure 20: I am required to learn about mobile technology as part of my work ............................... 39

Figure 21: I am required to use mobile technology as part of my work .......................................... 40

Figure 22: I would like more opportunities to use mobile technologies at work .............................. 40

Figure 23: My workplace supports the use of mobile technologies ............................................... 41

Figure 24: I support others within the workplace to use mobile technologies ................................ 41

Figure 25: The use of mobile technologies is compatible with my library's culture and values.......... 42

Figure 26: The use of mobile technologies would meet the needs of our library's customers better 42

Figure 27: Does your library provide a mobile app? 43

Figure 28: Library App for University of Auckland \& Massey University Libraries - rendered on Samsung Galaxy Gio

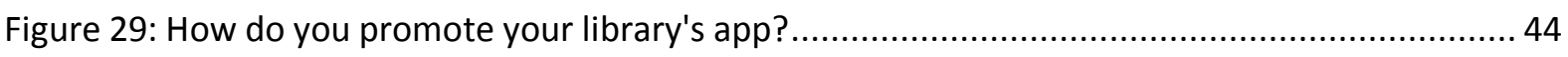

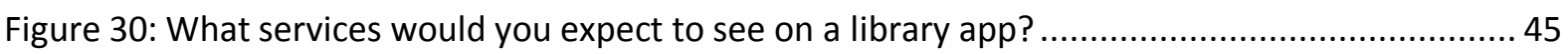




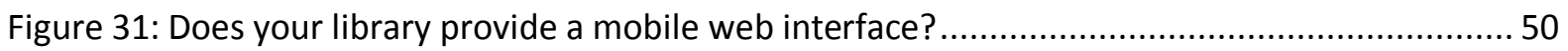

Figure 32: Which of your library webpages are optimised for use on a mobile device? .................... 50

Figure 33: How do you promote the library's mobile web? .............................................................. 51

Figure 34: What services would you expect to see on your library's mobile web? ............................ 51

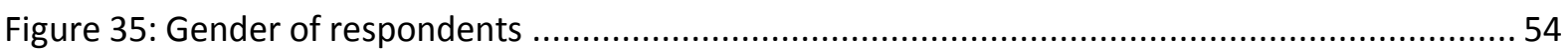

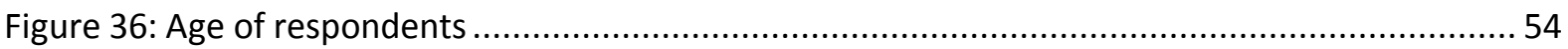




\section{Problem Statement}

\subsection{Rationale for the Study}

Mobile devices and their associated technologies are becoming common-place in today's connected society; impacting on the information seeking behaviour of individuals and signalling a change in the nature of information access. Increased costs associated with technology infrastructure, and the need to keep pace with technology has seen a shift in how Aotearoa New Zealand's educational institutes, at all curriculum levels, maximises its use of available technological resources. If the education model for the $21^{\text {st }}$ Century learner has evolved, the flow-on effect for the higher education libraries within Aotearoa New Zealand must be considered.

In a recent study of information-seeking behaviours of University staff and students, academic librarians at McGill University found the advancing nature of mobile technologies altered the information literacy landscape for its patrons; resulting in the need for, and development of, a modern hybrid literacy programme that detailed the benefits of mobile technology use within an academic library environment (Canuel, Crichton, \& Savova, 2012, p.36). This example highlights the changing nature of information access for the $21^{\text {st }}$ Century and suggests academic librarians need to be aware of these advances, and the impact it may have on their role as educator.

Within New Zealand, Secondary Schools, and more recently Intermediate Schools, have opted to employ a policy of 'Bring/Buy Your Own Device' (BYOD) as a means to manage technology infrastructure within their own institutional settings and engage with an ever-changing technological environment (Crown Fibre Holdings Limited, 2012; Wanganui Collegiate School, n.d.). Learners' within these environments will be mobile-savvy and, when transitioning to higher education, may have an expectation that the tertiary sector will follow the same educational learning model. The implication of directional change and a shift in the educational learning model for the tertiary sector therefore is significant.

What is unknown is how Aotearoa New Zealand's higher education libraries, as practitioners of information literacy education, will implement a shift in traditional service delivery to better serve the needs of its learners and validate its relevancy within the wider academic environment. 


\subsection{Research Objectives}

The objectives of this research are to investigate the adoption/non-adoption of mobile technologies within Aotearoa New Zealand's higher education libraries, and provide an opportunity to comparatively examine their use of innovative technologies in serving the needs of their community. Further, it is anticipated that this research will highlight key concepts and issues concerning 21 st Century pedagogy which may affect the professional developments needs of library staff and/or the organisational design of the higher education library within New Zealand. The extent to which library staff are supported and encouraged to adapt to a less traditional model of service delivery will also be explored.

\subsection{Research Questions}

This research will seek to explore:

- To what extent are Aotearoa New Zealand's higher education libraries currently using mobile technologies for the delivery of its information and research services?

- What impact, if any, do mobile technologies have on the professional development needs of higher education librarians?

- What models of practice, if any, exist for mobile technology use within Aotearoa New Zealand's higher education library environment?

\subsection{Theoretical Framework}

Rogers' Diffusion of Innovations theoretical framework has been selected for this research. This framework provides a holistic approach towards innovation adoption as evidenced in the findings for recent studies on the diffusion of Facebook as an innovation within New Zealand public libraries (Neo \& Calvert, 2012), and the diffusion of mLearning as an innovation influencing New Zealand higher education teaching staff and students (MacCallum, 2011, p.16). 
The six elements that form the main concepts for this research are defined below:

- Diffusion is defined as "the process in which an innovation is communicated through certain channels over time among the members of a social system" $(2003$, p.5).

- Innovation is defined as "an idea, practice, or object that is perceived as new by an individual or other unit of adoption" (Rogers, 2003, p.12). The concept of innovation refers to the adoption of mobile technologies with Aotearoa New Zealand's higher education libraries.

- Technology Cluster is defined as consisting of "one or more distinguishable elements of technology that are perceived as being closely interrelated" (Rogers, 2003, p.14). The concept of technology clusters refers to mobile apps and the mobile web interface.

- Communication Channel, in terms of diffusion, is defined as the process by which information exchange about a new idea is communicated between members of a social system (Rogers, 2003, p.18).

- Time is defined as the progressive behavioural state from which knowledge of an innovation is gained, passed on, and adopted or rejected, within a social system (Rogers, 2003, p.20).

- Social System is defined as a "set of interrelated units that are engaged in joint problem solving to accomplish a common goal" (Rogers, 2003, p.23). The concept of social system refers to the higher education library with its members including Teaching and Technical Librarians, and Information Technology staff.

\subsection{Definition of Terms}

For the purpose of this research, the following definitions will be applied:

$21^{\text {st }}$ Century pedagogy / learner: refers to the shift away from instructor-led educational instruction towards a fluid participatory learning environment of co-creation, co-learning, collaboration and transparency (Bolstad et al., 2012). 
Information Technology Staff: refers to library-based or library-focused IT staff responsible for providing mLearning instruction, such as mobile device connectivity, within a higher education library environment.

Mobile apps: "are applications designed to run specifically on a mobile operating system ... delivering a specific functionality" (Pacansky-Brock, 2013, p.138)

Mobile learning / mLearning: "is the acquisition of any knowledge or skill through using mobile technology, anywhere, anytime, that results in an alteration of behaviour" (Geddes, 2004, p.1).

Mobile technology: refers to mobile-computing application software that facilitates access to, and sharing of, information on portable hand-held internet-capable wireless computing devices (hardware) (Wiebrands, 2012, p.3).

Research and information literacy education: refers to the sharing of skills to locate, identify, retrieve and evaluate scholarly information of academic benefit by a teaching librarian to a cohort of students' (The Council of New Zealand University Librarians, 2006).

Teaching Librarian: refers to a qualified or registered librarian who holds a professional role within an higher education library and actively provides information literacy instruction within an higher education library environment (Careers NZ, 2013; Library and Information Association of New Zealand Aotearoa, n.d.).

Technical Librarian: refers to a qualified or registered librarian who holds a professional role within a higher education library that actively supports the library's digital technology services (Library and Information Association of New Zealand Aotearoa, n.d.; Liu \& Cai, 2013, p.23).

\subsection{Delimitations / Limitations}

The following assumptions and limitations have been applied to this research:

1. Due to the INFO 580 project scope and limited time constraints, this study limits participation to 29 New Zealand higher education libraries. A more in-depth study of all 
higher education libraries, including Government Training Establishments, Private Training Establishments, and Māori Education Providers may provide a more comprehensive analysis of mobile technology integration for the New Zealand higher education library sector.

2. A dedicated mobile-web interface was located for a small number of library homepages, identified by the prefix/suffix ' $m$ ' in the library URL. This method of site entry presents the user with a basic display of web content optimised for viewing on a mobile device. However, as these URL links were not provided on the Directories of New Zealand libraries online database, they were omitted from analysis with the W3C tool.

3. Contact was received from one Library Manager requesting the survey questionnaire timeframe be extended past Sunday 6 October 2013 in order for notification to be passed on to their library staff. As the Human Ethics Committee had granted approval for the timeframe specified, the request was declined, and may have resulted in the exclusion of library staff from one higher education library from participating in this research.

4. The participant sample is limited to teaching librarians, technical librarians and IT staff employed at one of 29 higher education libraries. Increasing the participant sample population via random sampling may provide a more representative data set for analysis. 


\section{REVIEW OF THE LITERATURE}

This section of the research examines four elements of the mobile environment significant within an educational context: Pedagogy of the $21^{\text {st }}$ Century Learner, Technology Trends, Mobile Technologies in Use in Education and Library Staff supporting the Ubiquitous Learner.

\subsection{Pedagogy of the $21^{\text {st }}$ Century Learner}

The New Zealand Government's vision for tertiary learners is one of inclusivity whereby higher education learning must build upon the foundation of learning established at (secondary) school in order to meet the diverse needs of all groups it serves. Furthermore, its aim of inclusivity asserts that all New Zealanders, regardless of background, should have equitable access to, and the opportunity to gain, world-class skills and knowledge from its higher education providers (Ministry of Education, 2010, p.6). For higher education libraries, an understanding of pedagogical environments associated with $21^{\text {st }}$ century learners is essential in building upon, and maintaining, the learning foundations created at secondary school level.

In a recent report, the New Zealand Council for Educational Research highlighted that the future oriented perspectives of knowledge and learning are challenging the traditional view of information sharing, evolving into a more collaborative and exploratory model of co-learning (Bolstad, et al., 2012, p.39). Further research supports the notion of a paradigm shift in New Zealand education that will redefine the role of the educator into one that must adapt and evolve; driven by increasing exposure to global information networks and advancements in technology (Johnson, Adam, \& Cummins, 2011, p.2; MacCallum, 2011, p.7).

Several studies support the notion that the rapid advancement and increased popularity and access to mobile technologies for leisure significantly influences the teaching and learning landscape; shifting the boundaries of digital literacy into a wireless learning environment accessible anywhere and anytime (Johnson, et al., 2011, p.7-8; Laurillard, 2007, p.152; Wiebrands, 2012, p.4). Additional research further suggests, whilst students may or may not carry portable computers to their educational institute, they almost always carry mobile phones (Lippincott, 2010, p.209; United Nations Educational Scientific and Cultural Organization, 2012, p.9). 


\subsection{Technology Trends}

In its 2011 technology report for the New Zealand tertiary sector Johnson, Adam \& Cummins signal collaborative online learning environments, mobile apps and tablet computing as significantly relevant to the future of New Zealand teaching, learning and research; proposing likely adoption for the tertiary sector within one year $(2011$, p.2). These findings suggest information will be retrieved from multiple online resources, alluding to the use of both formal and informal information networks within collaborative learning spaces $(2011$, p.6).

Overseas, Universities are cited as exemplars of mobile apps in practice clearly indicating these technologies are actively used and supported within the education sector (Johnson, et al., 2011, p.7). Interestingly, two New Zealand University libraries, Massey University Library in 2011 and the University of Auckland Library in 2010, both modelled mobile apps in practice although they had not been included within the New Zealand exemplar section (Boopsie Inc, 2012a, 2012b; Johnson, et al., 2011, p.7). Further, both Massey University and the University of Auckland have adopted wireless computing network access to accommodate tablet computers; considered a new category of mobile device tipped as the learning tool of choice for learner engagement outside of the classroom (Johnson, et al., 2011, p.8; Massey University, n.d.; University of Auckland, n.d.).

A recent mobile consumer trends report from Google indicates that 2 out of 5 New Zealanders currently own a smartphone and that $80 \%$ of smartphone users actively utilise their mobile phone to locate information $(2012$, p.2). Freedom of mobility (80\%) and access to social networks (77\%) rated highest amongst smartphone users $(2012$, p.9, 19). Interestingly, $38 \%$ of participants surveyed, the largest group identified, held an undergraduate or postgraduate degree suggesting mobility and connectedness is valued by alumni. In addition $11 \%$ of participants identified their current employment status as student $(2012$, p.42) suggesting that New Zealand learners, though small within this population sample, are familiar with, or comfortable using, smartphone technology to locate, identify, retrieve and evaluate information of interest.

\subsection{Mobile Technologies in Use in Education}

In proceedings from the International Association of Scientific and Technological University Libraries [IATUL] 2012 conference, Wiebrand suggests the increased popularity of mobile devices, acquired and used by tertiary learners' in a social context, provides an opportunity for higher education 
libraries to transform its provision of services; supporting the learners' information needs, anytime, anywhere. The author's findings further suggest that whilst both mobile apps and the mobile web provide opportunities to better engage with learners', mobile web development in its current state provides a superior level of connectivity $(2012$, p.4). Implications for the higher education library suggest mobile web development should be a priority; extending the library into a mobile connected environment.

In a study on the influences and adoption of mobile technology by New Zealand teaching staff and students, MacCallum's findings led to the development of six strategies recommended as key considerations for tertiary education providers when incorporating mobile technologies into the learning environment (2011, p.217):

1. Focus on ease of use and remove obstacles

2. Promote the benefits of mobile learning

3. Develop strategies to ward negative attitudes

4. Support educators

5. Utilise the novelty factor of mobile technologies

6. Scaffold student learning with mobile devices

These same strategies may serve to guide the New Zealand higher education library towards a participatory mobile environment.

\subsection{Library Staff supporting the Ubiquitous Learner}

The mission of the higher education library is "to support the learning, teaching and ... research of their parent institution" (Oakley \& Vaughan, 2007, p.43) and is echoed through the vision and mission statements held by Aotearoa New Zealand's higher education libraries. The means, by which this goal is achieved within the academic teaching and learning community, must be considered in terms of the virtual library environment in addition to the physical library.

In a recent study of New Zealand and Australian ITP library staff, Saravani and Haddow (2011) suggest the increased use of mobile technologies is impacting on the organisational design of the higher education library and the preparedness of library staff to support the mobile learner. Participants within this research were surveyed for their responses to technology adoption, and the 
specific skills and training required, for the delivery of mobile technologies. The authors' findings suggest librarians' were expected to be familiar with technology from both the perspective of their up-line manager and the library customer (2011, p.185). Further, librarians' expressed a genuine interest in acquiring and developing appropriate skills to assist the library customer within the mobile environment, suggesting whilst the delivery platform was central, maintaining a high level of service provision was of primary concern (2011, p.186). Similarly, Dresselhaus \& Schrode, in their study of mobile technologies and academia, acknowledge library staff require a particular skill set though suggest it may be the responsibility of the librarian to become self-directed in their learning of mobile technologies in order to support these services within the workplace $(2012, p .96)$.

Maintaining a high level of service provision by undertaking technology-focused professional development to up skill and maintain relevancy were identified as influential factors by New Zealand library staff when selecting professional development opportunities (Roser, 2012, p.17). Further, in discussing the long term future of libraries, the author's findings indicate New Zealand librarians' do not feel threatened by forecast changes to learner environments, rather, there is a perception that New Zealand libraries are flexible and evolving to adapt to these changes $(2012$, p.18).

By contrast, New Zealand's aging library workforce and a shift towards library staff profiles that focus less on professional librarianship, and more on technology-based competency have been identified as significant considerations for the higher education library's service model of the future (Barthorpe, 2012, p.3-4) and supports discussion of the future ubiquitous library, where librarians, patrons and information content, engage collaboratively within a mobile environment (Barnhart \& Pierce, 2012, p.562).

In summary, the review of literature highlights the importance of understanding the evolving needs of the $21^{\text {st }}$ century learner and the significance of building upon pre-established foundations of learning. As technology rapidly pervades modern society and the social context of learners, the higher educational learning environment and the role of the higher education librarian as educator is transforming. Mobile technology is changing the information seeking behaviour of learners; seeking information anytime, anywhere. Overseas, higher education institutes and their libraries are transforming their service provisions to meet learners at point of need, on the learners' terms. Within New Zealand, higher education librarians' possess an awareness of the transformation taking shape; recognising the degree of flexibility required to evolve and adapt to a mobile environment. 


\section{RESEARCH DESIGN}

The research was conducted using a transformative mixed method design approach utilising two data sets; first, a quantitative analysis of library homepages and, second, qualitative and quantitative questioning of library staff. This method of research design was selected as the analysis of data set one was likely to inform the data collection for data set two (Creswell, 2014, p.230).

\subsection{Research Sample}

The two sample data sets were identified as the i) library homepage, and ii) the library staff, belonging to the library associated with one of 29 named New Zealand higher education providers.

\section{Data Set 1: New Zealand higher education library - library homepage}

A preliminary investigation into the provision of a mobile web interface and/or mobile app was undertaken using eight New Zealand University library websites. This data suggests each of the eight New Zealand University libraries' provides access to mobile technologies to some degree. However, following consultation with my supervisor, $\mathrm{Dr}$ Brenda Chawner, the sample group was extended to include all New Zealand Institutes of Technology, Polytechnics and Wānanga in order to gain a more comprehensive data set for analysis. Therefore, the sample group includes the library website, specifically library homepage, associated with the following 29 higher education providers (New Zealand Qualifications Authority, n.d.-b):

\begin{tabular}{|l|l|}
\hline University (8) & Auckland University of Technology \\
& Lincoln University \\
& Massey University \\
& University of Auckland \\
& University of Canterbury \\
& Victoria University of Wellington \\
& University of Waikato \\
& University of Otago \\
\hline Institute of Technology / & Aoraki Polytechnic \\
\hline
\end{tabular}




\begin{tabular}{|c|c|}
\hline Polytechnic (18) & $\begin{array}{l}\text { Bay of Plenty Polytechnic } \\
\text { Christchurch Polytechnic Institute of Technology } \\
\text { Eastern Institute of Technology / Tairawhiti } \\
\text { Polytechnic } \\
\text { Manukau Institute of Technology } \\
\text { Nelson Marlborough Institute of Technology } \\
\text { Northland Polytechnic / NorthTec } \\
\text { Open Polytechnic } \\
\text { Otago Polytechnic } \\
\text { Southern Institute of Technology } \\
\text { Tai Poutini Polytechnic } \\
\text { Unitec Institute of Technology } \\
\text { Universal College of Learning } \\
\text { Waiariki Institute of Technology } \\
\text { Waikato Institute of Technology } \\
\text { Wellington Institute of Technology } \\
\text { Western Institute of Technology at Taranaki } \\
\text { Whitireia Community Polytechnic }\end{array}$ \\
\hline Wānanga (3) & $\begin{array}{l}\text { Te Wānanga o Aotearoa } \\
\text { Te Wānanga o Raukawa } \\
\text { Te Whare Wānanga o Awanuiarangi }\end{array}$ \\
\hline
\end{tabular}

Due to the project scope and limited time constraints associated with this proposed research, organisations classified as Government Training Establishments, Private Training Establishments, and Māori Education Providers (with the exception of Wānanga) have been excluded (New Zealand Qualifications Authority, n.d.-a).

\section{Data Set 2: ITS Staff, and Technical and Teaching librarians}

Participants for this research were sourced from teaching librarians, technical librarians and librarybased or library-focused Information Technology Services (ITS) staff, currently employed by, or located in, a library attached to one of the 29 Aotearoa New Zealand nominated higher education providers. 
Teaching and technical library service staff may be considered as most likely to be involved in frontline interaction with library customers, including but not limited to providing research support, information literacy instruction, and online research help.

The inclusion of library-based or library-focused ITS staff within the participant sample allows for variances that may occur with the organisational design of each higher education library. For example, the Library Information Desk at Massey University's Manawatū Campus accommodates both professional librarians and library-based ITS staff. Computer-related queries, including wireless connection issues, are directed to professional librarians in the first instance. Where these queries are outside the scope of the librarian to solve, they are then referred to ITS staff for advanced assistance. However, if the librarian is engaged in other duties, library customers will often approach ITS staff directly (Massey University Library, 2009, p.9). The contribution of library-based ITS staff may be significant in terms of identifying and highlighting unknown mobile technology-related issues.

\subsection{Data Collection}

\section{Data Set 1: New Zealand Higher education library websites}

This section of the research was undertaken using a content analysis design approach. This approach seems best suited to explore and identify the specific intentions and visual characteristics of each library website when examined against defined criteria. This also permits the researcher a systematic and more objective approach to analysis (Leedy \& Ormrod, 2010, p.144).

The library homepage for each library was purposefully selected as the most likely start point for library users and did not require user authentication. The library URL was obtained from the Directories of New Zealand Libraries online database (National Library of New Zealand Te Puna Mātauranga o Aotearoa, n.d.). Web links for each library were followed to check accuracy and validity using a desktop computer.

The W3C MobileOK Checker tool was purposefully selected to assess the degree of conformance of mobile-friendly web content provided on each library homepage as defined by the Mobile Web Best Practices 1.0 guidelines (Best Practices Working Group \& W3C, 2008a). The tool functions by testing HTML content over HTTP and was selected as it provides a measure of web content specifically for 
the mobile environment and can be used to assess the usability of the existing website on a mobile platform, and provide recommendations to improve the overall user experience (Best Practices Working Group \& W3C, 2008c).

The library homepage URL was entered into the W3C tool using a desktop computer for each library to perform analysis. Following analysis, conformance results were then manually entered into a Microsoft Excel spread sheet and descriptive statistics generated.

The W3C MobileOK Checker tool (http://validator.w3.org/mobile/) was used to assess the page size and network usage of each library homepage, and identify web content performance issues likely to impact the mobile user experience. The W3C tool categorised performance issues into one of four levels of severity (W3C, n.d.-d):

1. Critical - Page does not render in part, or does not render in a reasonable timeframe

2. Severe - Page renders but user experience is impacted

3. Medium - Consideration should be given to a mobile constraint

4. Low - Useful improvements are possible

At the highest level, critical severity failures indicate that most mobile devices will not render the page content in full, or will not render the page content within a reasonable time frame. For the purpose of this research, only the severity failures indicated as 'critical for each library homepage were examined as these failure types were most likely to negate the overall user experience.

Examination of the library homepages using W3C MobileOK Checker tool occurred during September 2013.

Three mobile devices were used to access each library homepage and examine how these visually rendered to a mobile user. Apple Inc, running iOS and Google, running Android (Apple Inc., n.d.; Google, n.d.)., are the two major developers within the mobile operating system market. For the purposes of data analysis both mobile operating systems were tested by the researcher. The three devices available for use by the researcher were: 


\begin{tabular}{l|lll|} 
Device Name & iPod Touch 4th & Samsung Galaxy & Samsung Galaxy Note \\
& Generation & Gio & 10.1 \\
\hline Device Type & Media Player & Smartphone & Tablet \\
Model Type & MC540ZP & GT-S5660 & \\
Display Size & 3.5 & 3.2 & 10.1 \\
(inches) & & & \\
Operating System & iOS 5.1.1 & Android 2.3.6 & Android 4.0 Ice Cream \\
& & Gingerbread & Sandwich \\
Browser & Default Safari HTML & Default Android & Default Android HTML \\
& & HTML & \\
Auto-fit Pages & - & Disabled & Disabled \\
Zoom & Enabled & Medium & Medium \\
Text Encoding & - & Auto-Detect & Auto-Detect \\
Block Pop Up & Yes & Yes & Yes \\
Windows & & & Yes \\
Load Images & - & Yes & Enabled \\
Javascript & Enabled & Wi-Fi Only & Wi-Fi Only \\
Connectivity & & &
\end{tabular}

Figure 1: Mobile devices used to examine Library Homepage rendering

The above devices utilise multi-touch screen technology permitting the user to interact directly using either gesture-based movements (all devices) or a stylus (Samsung Galaxy Note 10.1 only). Internet connectivity to browse webpages was predominantly made via Wi-Fi connectivity. Where Wi-Fi was unavailable for testing, a portable Wi-Fi hotspot was accessed via a mobile access point tethered to the Samsung Galaxy Gio's 3G network.

Using the default installed mobile web browser, the library homepage URL was manually entered into the mobile device web address bar for each of the three devices and a screen capture taken using the HOME + POWER keys (iPod Touch and Samsung Galaxy Gio), and the pre-installed MULTIFUNCTION KEY (Samsung Galaxy Note 10.1) to examine each library's rendering of its homepage. 


\section{Data Set 2: ITS Staff, and Technical and Teaching Librarians}

For this section of the research, a survey questionnaire (see Appendix 3 and 4) was developed to examine the extent to which library staff were required, supported and/or encouraged to adapt to a less traditional model of service. In addition, the attitudes, perceptions and experiences in using mobile technology by library staff were also explored.

Approval from the Human Ethics Committee was sought, and granted, for the survey questionnaire prior to its distribution. The survey questionnaire itself was created and managed using the Qualtrics research software registered to Victoria University of Wellington (https://vuw.qualtrics.com).

The survey questionnaire used four tools for the measurement of response variables:

1. Multi choice questions with single response (logic qualifiers applied)

2. Multi choice questions with multi response

3. Question statements with Likert Scale

4. Open-ended questions

Logic qualifiers were applied to some questions enabling respondents to progress through, or exit the survey, based on the previous answer selected. For example, using the multi choice single response question 'Does your library provide a mobile app?' logic qualifiers were applied to the multi choice answers available where:

- If respondent selects $\underline{\text { YES }}$ then

○ Show question: 'How do you promote your library's app?' then

○ Hide question: 'What services would you expect to see on a library app?'

- If respondent selects $\underline{\text { NO }}$ or IDON'T KNOW then

- Hide question: 'How do you promote your library's app?' then

○ Show question: 'What services would you expect to see on a library app?'

Participants were invited to complete the survey questionnaire online between Monday 9 September 2013, and Sunday 6 October 2013. The questionnaire included an information statement 
outlining the scope of the research and informed participants of their right to withdraw at any time without negative consequence and provided a guarantee that any response provided would remain anonymous and confidential (Leedy \& Ormrod, 2010, p.145).

An incentive of a Mighty Ape $\$ 50.00$ gift voucher was offered to respondents by way of a single prize draw in recognition of their time to complete the survey. Entry to the draw was included at the end of the survey and was optional for each respondent to enter into.

Participants were contacted and invited to participate in the online survey through the following communication channels:

1. Direct email to the Library Manager of each New Zealand higher education library (see Appendix 1) requesting their assistance with staff participation in completing the survey and;

2. Direct email to the following New Zealand library mailing lists: NZ-Libs, TRW-general, TelSIG (see Appendix 2)

A reminder notification to participate in the research study was sent two weeks prior to survey close to each Library Manager. The announcement of one reminder notification by the researcher was included in the initial contact. The reminder notification was sent to all Library Managers, with the exception of 1 , who elected to opt-out of participation following the initial contact.

\subsection{Data Analysis}

\section{Data Set 1: New Zealand higher education library websites}

Data obtained from the W3C MobileOK Checker tool was manually organised into a series of Microsoft Excel spread sheet tables. Values for each variable were entered as either:

1. A numeric value sorted into ascending order, for example, Page Size (Kilobyte) where the numeric value for Library (1) $=41$ 
2. A percentage value, for example, Page Size Content Analysis (measured at $\mathbf{1 0 0} \%$ ) where the percentage value for Library (1) = Images 54\%, Style Sheet 10\%, Document $36 \%$

Graphical charts were then generated to illustrate the data findings for each of the 29 higher education libraries, represented anonymously by the numeric codes: 1 to 29 .

\section{Data Set 2: ITS Staff, and Technical and Teaching Librarians}

Due to anomalies with the display of data obtained from survey participants via Qualtrics, and at the recommendation of supervisor Dr. Brenda Chawner, a CSV format of raw data was created, examined, then imported into Microsoft (MS) Excel and secured with a password.

Using MS Excel, the raw data was then manually organised into tables and the frequency of participant responses, expressed as a percentage, were used as a measurement tool. Graphical charts were then created to illustrate the data findings within this research report.

Data from open-ended questions were examined for patterns and are grouped into significant themes within this research report. 


\title{
8. FINDINGS \& DISCUSSION
}

\author{
8.1. Library Websites
}

\subsubsection{Research Question 1: To what extent are Aotearoa New Zealand's higher} education libraries currently using mobile technologies for the delivery of its information and research services?

To address the first research question, the page size and network usage of each library homepage was analysed for conformance to W3C Mobile Web Best Practice 1.0: Basic guidelines (Best Practices Working Group \& W3C, 2008a). The purpose of the guidelines is to aid in a consistent approach towards the user experience on a mobile platform. Variances in mobile device hardware, operating systems, and platforms for internet access impact heavily on a user's experience of the mobile web and often applications intended for one platform can be challenging to adapt to another (Chittaro, 2006, p.40; Kroski, 2008, p.8; Paterson \& Low, 2011, p.420).

What is the page size of the library homepage?

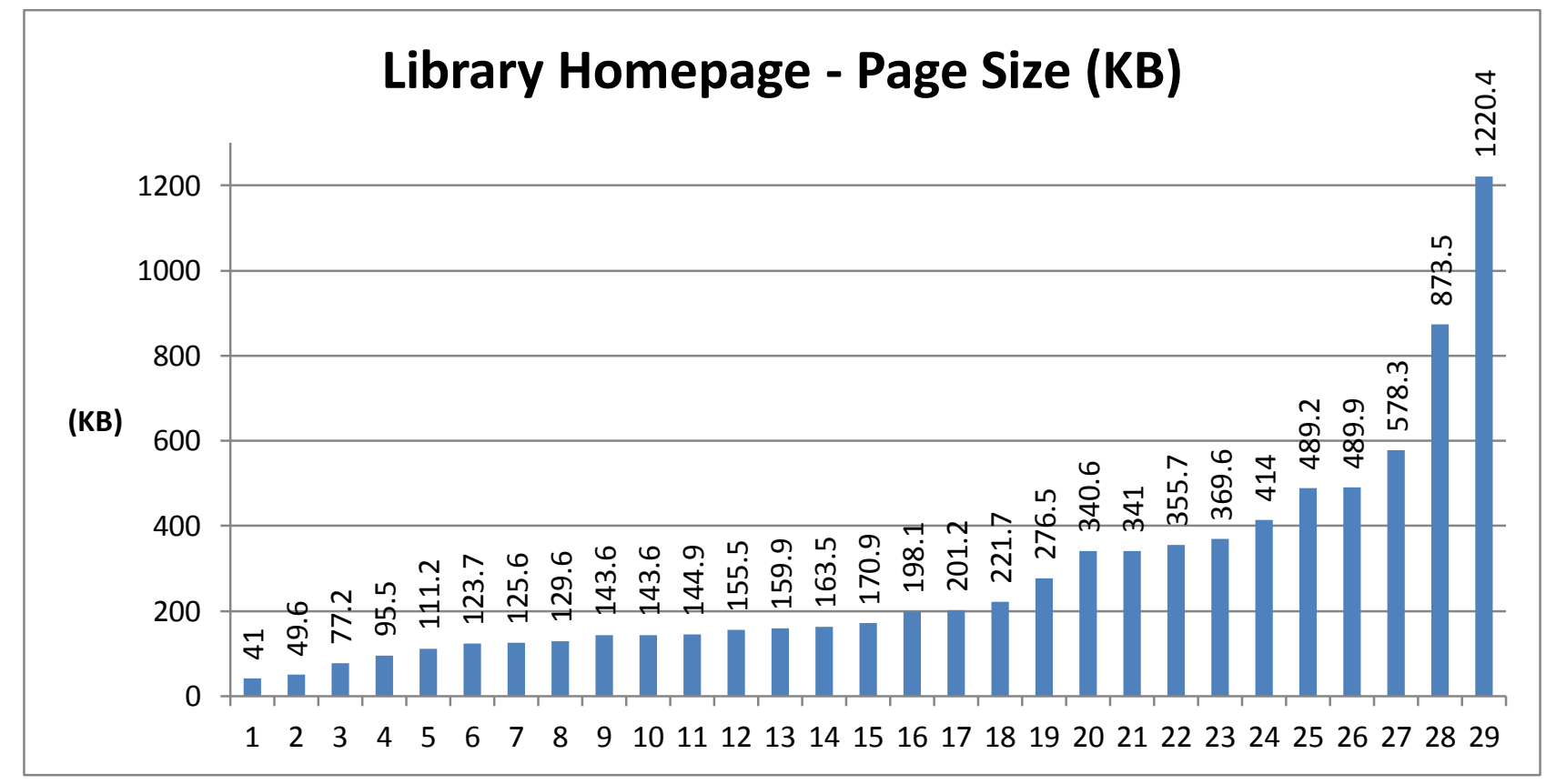

Figure 2: Library Homepage - Page Size (KB) 
Library homepages presently range in size from $41 \mathrm{~KB}$ to $1.2 \mathrm{MB}$ (see Figure 2). Of the 29 library homepages analysed, none conformed to the recommended W3C best practice guidelines of maximum page size $=20 \mathrm{~KB}$.

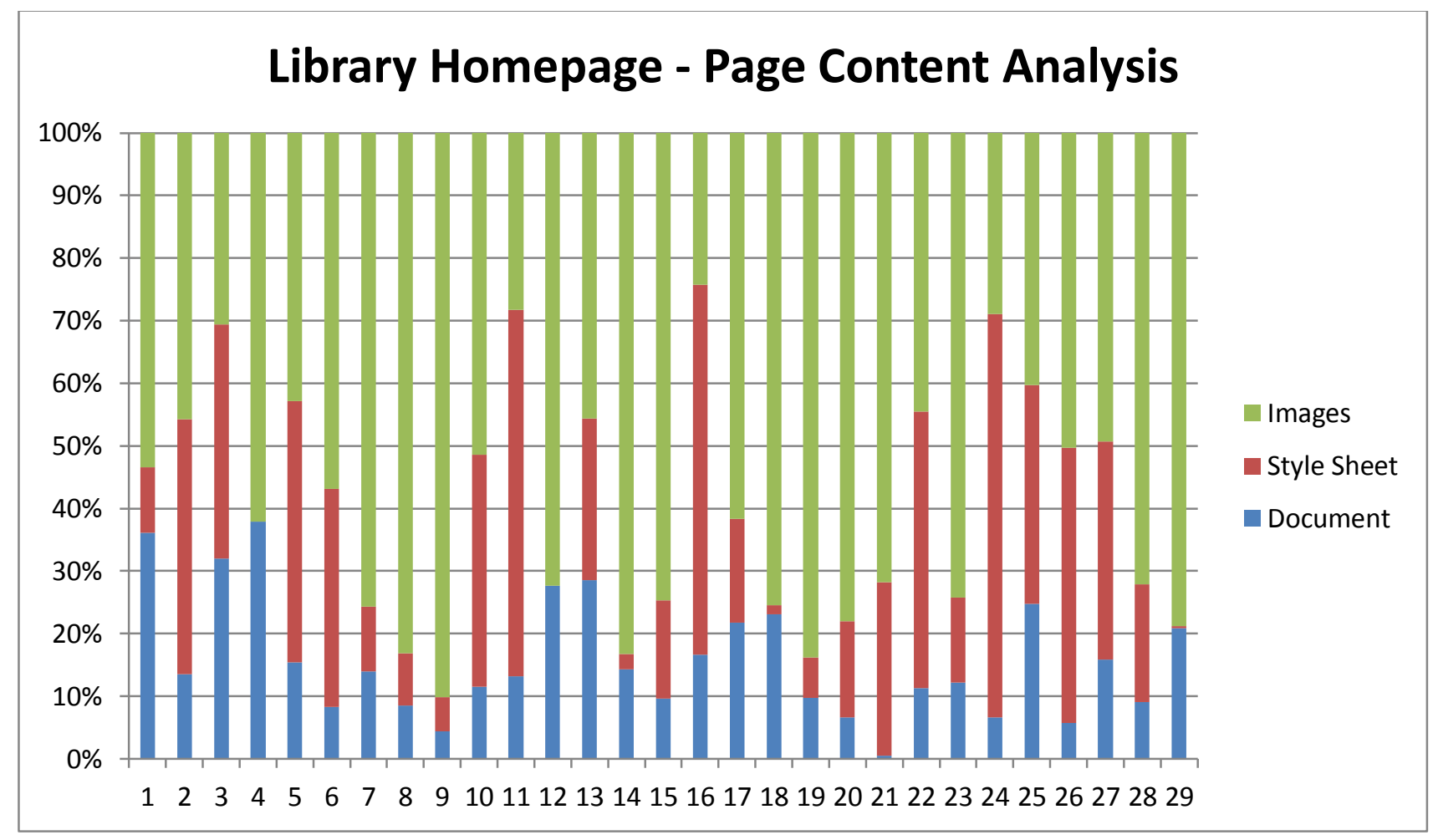

Figure 3: Library Homepage - Page Content Analysis

An examination of the library homepage content shows each homepage is comprised of document mark-up, style sheet and images (see Figure 3). For 18 libraries, at least $50 \%$ of page size can be attributed to the use of images. For 5 libraries, this increases to $80 \%$ or more of page size. The implication of using multiple or high resolution graphics for the mobile user is increased bandwidth consumption and, potentially, higher user charges. Further, these graphics may not render properly on smaller mobile devices due to screen size, resulting in confusion and dissatisfaction when navigating the homepage.

Whilst these findings support the assertion that the majority of New Zealand higher education library homepages are content-heavy (Howie, 2013, p.5), it also illustrates web-based library homepages in their current state may not transition well to a mobile-web platform. For the mobile user, the implication of a content-heavy and unresponsive web design is an increased likelihood of latency, resulting in a decreased level of system usability and satisfaction (Best Practices Working Group \& W3C, 2008b). 


\section{Total Critical Failures}

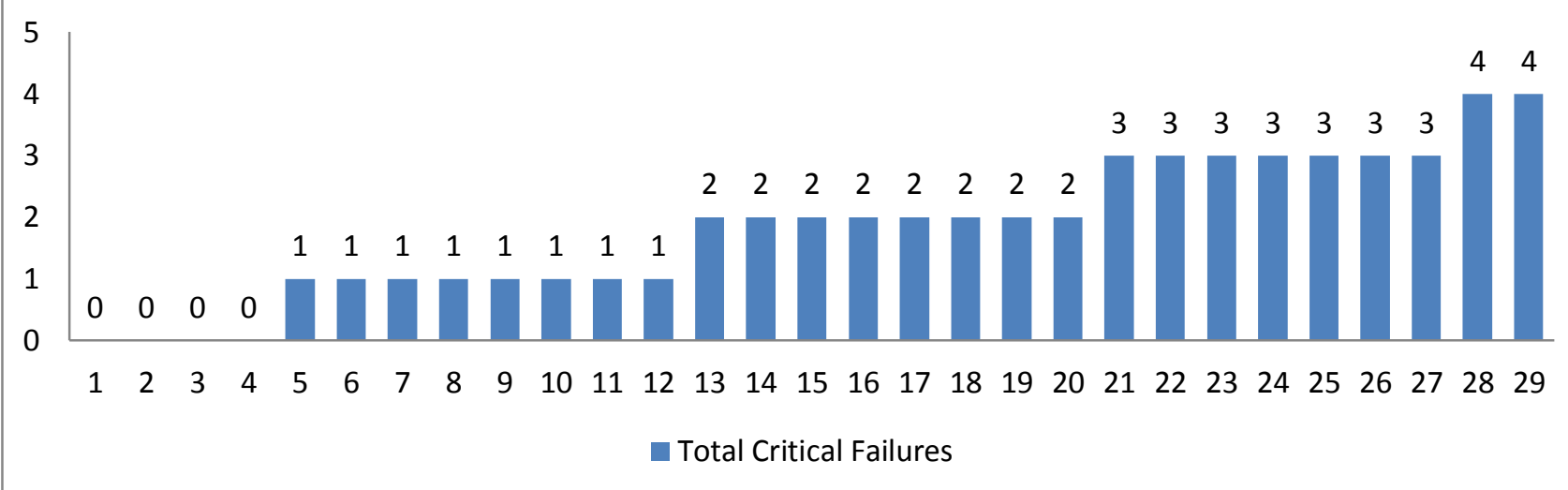

Figure 4: Library Homepage - Total Number of Critical Errors

The W3C tool provides a measure to assess the level of interoperability of the library's standard HTML website to a mobile-friendly environment; assigning a 'pass' or 'fail' grade for each criteria checked. Figure 4 shows that $87 \%$ of library homepages in their current state were assessed at a 'fail' level, having one or more critical failures when tested for conformance to a mobile environment. The severity level of 'critical' indicates that a mobile device is unlikely to render all or part of a webpage within a reasonable timeframe; however, a critical failure, once remedied, will improve the user experience of viewing a webpage on a mobile device (W3C, n.d.-a).

\section{Library Homepage - Critical Failures By Type}

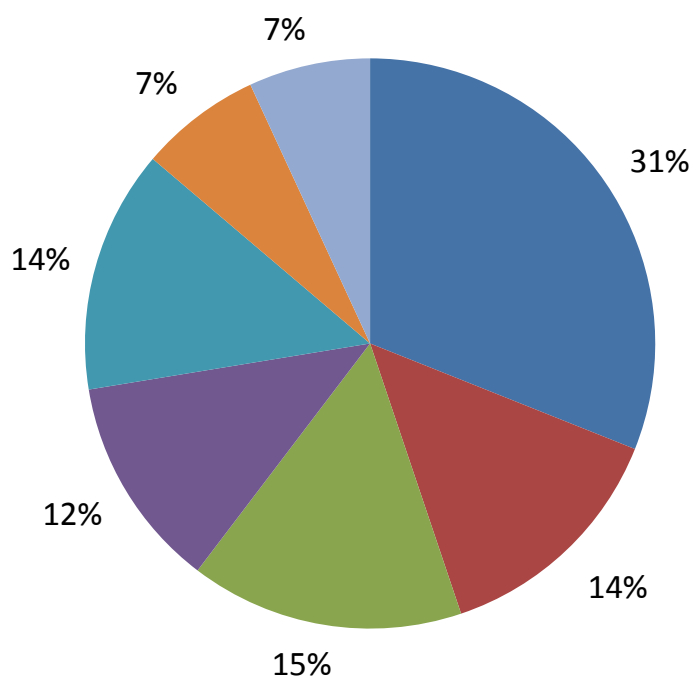

Page Size Limit

- 404 Not Found

External Resources

- No Frames

- Image Maps

Valid Markup

- No Critical Errors

Figure 5: Library Homepage - Critical Failures by Type 
Figure 5 identifies the library homepage critical failures by type. Of the 29 library homepages tested, only 4 (7\%) were assessed as having no critical errors. In conformance to a mobile environment, high levels of network latency experienced with external resource retrieval (15\%), broken web and broken embedded links (14\%), and a lack of platform interoperability with the use of frames (12\%) and image maps (14\%) account for over half of the critical failures presented. For the remaining 25 libraries, these findings posit that the mobile user will experience a decreased level of satisfaction when accessing the library homepage on a mobile device in its current state.

What are the number of network requests (to render) the library homepage?

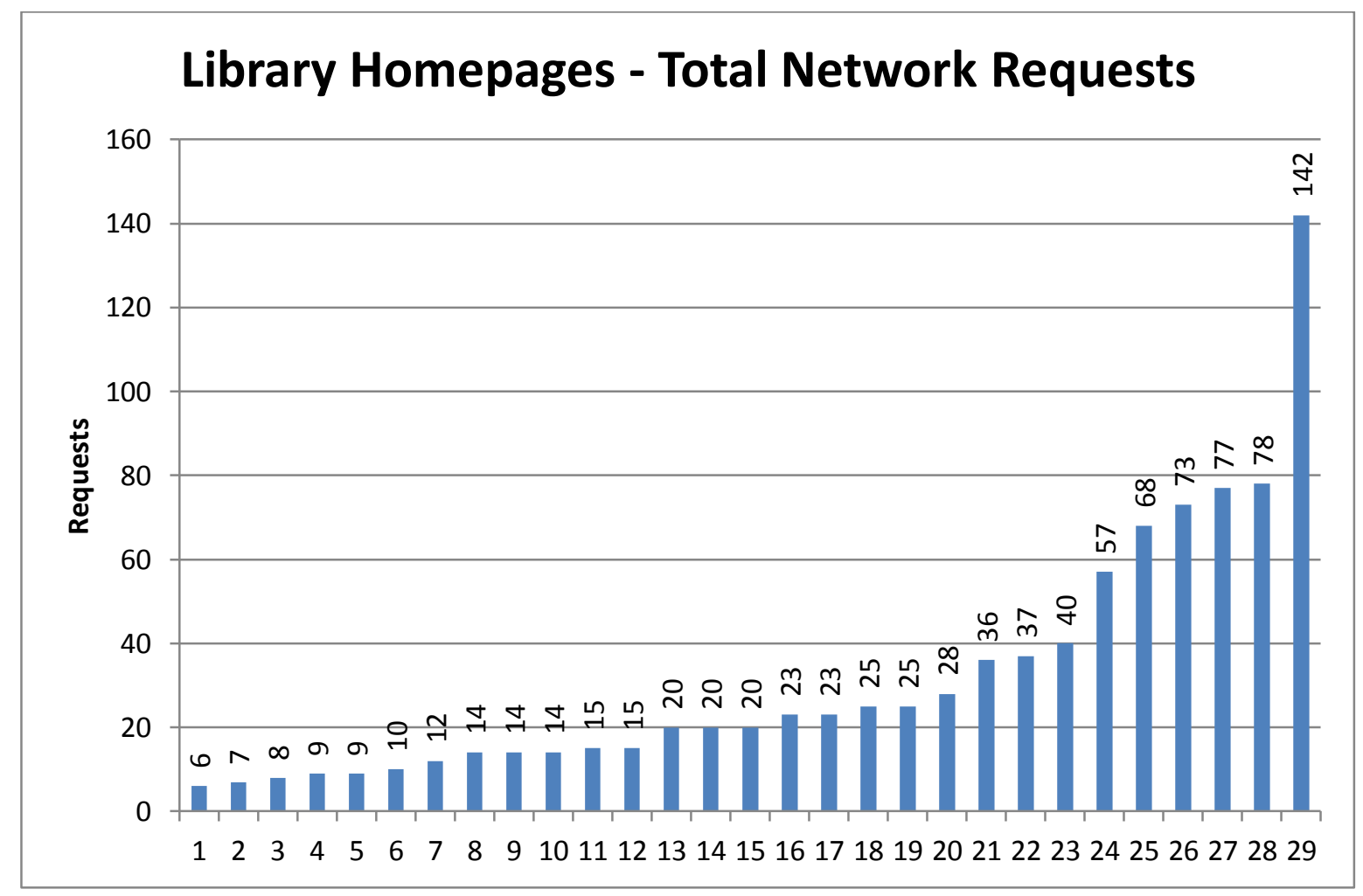

Figure 6: Library Homepage - Total Network Usage (Number of Requests)

The network usage analysis refers to the number of requests sent from a mobile device to a server in order to successfully render a webpage (see Figure 6). The total network requests for the 29 libraries ranged from 6 to 142 . Nine libraries measured above the network request average value of 32. The implication for the user of high volume network requests is the likelihood of increased latency caused by network data processing. In addition to delays in page rendering, latency is also likely to impact mobile data consumption limits available to the user. 


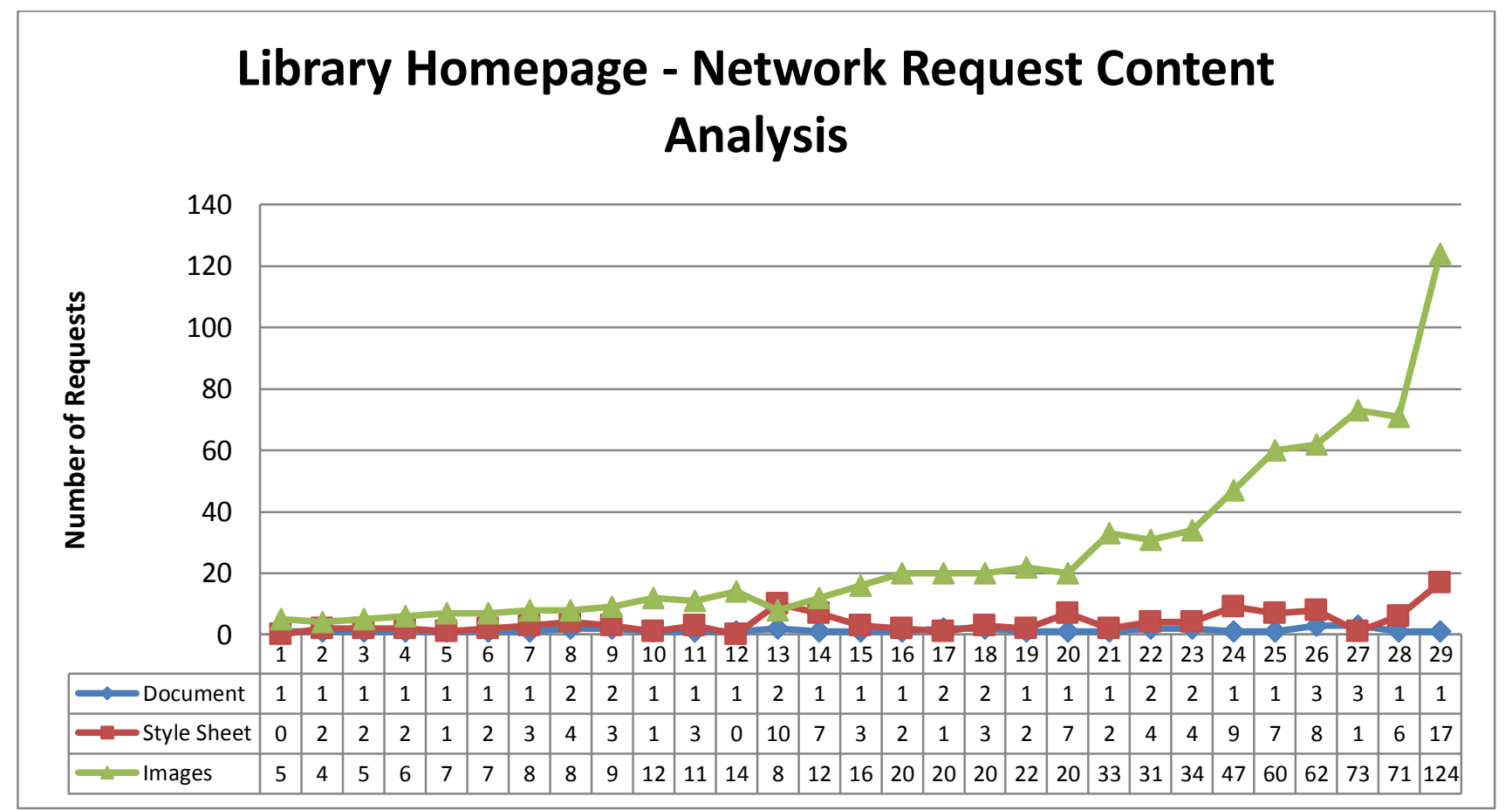

Figure 7: Library Homepage - Network Usage Content Analysis

Figure 7 shows an analysis of content within a network request is comprised of document mark-up, style sheets and images. Document mark-up refers to the computer language used to describe elements, or features, of a web document (Tech Terms, 2011). Style sheets, used to standardise the appearance of a webpage or group of webpages, aids in web usability during the user navigation process (W3C, n.d.-b). The use of document mark-up and style sheets is important to the overall user experience as it offers a degree of consistency of webpage presentation over multiple platforms (W3C, n.d.-c).

A correlation between content load, specifically, the number of images on a page, and the number of network requests required to render the page can be seen in Figure 7. At the lower end, one institute required only 6 network requests to render its homepage with 5 requests attributed to images. Conversely, another institute required 142 network requests during analysis to render its homepage with 124 requests attributed to image content contained within the webpage. 


\section{Wireless Network Access - On-Campus}

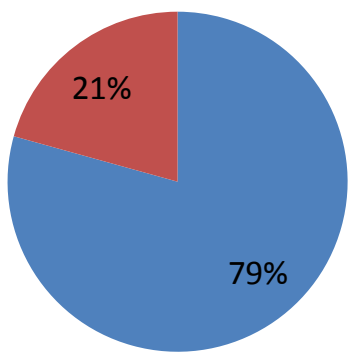

Wireless Access

No Wireless Access

Figure 8: Wireless Network Access - On-campus

Wireless network access (on-campus) provides higher education learners', located within the physical library, with the freedom to maximise their mobile device as an information seeking tool supporting 'anywhere, anytime' access to the virtual library, whilst conserving the user's mobile data consumption costs. Figure 8 shows that an institutional wireless network is currently unavailable to 1 in 5 New Zealand higher education providers and, by default, their associated library. For the library, this may result in an increased demand for hard-wired computers located within the physical library environment. For the physical library user, an increased demand to access limited computing resources is likely to result in increased waiting times and may be perceived as inconvenient. For the mobile and virtual library user, a lack of connectivity may be perceived as a barrier to accessing information further increasing user dissatisfaction.

Scrolling
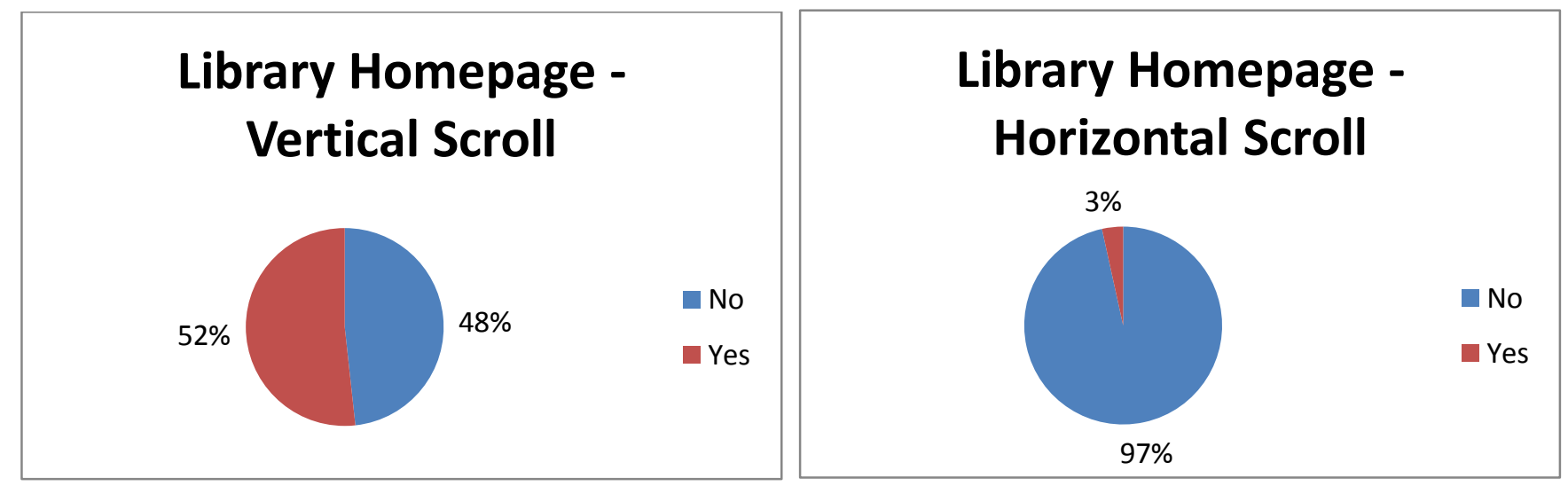

Figure 9: Library Homepage - Vertical and Horizontal Scroll on the iPod Touch 
Scrolling on a mobile device requires the user to gesture a swipe-motion (Lee, n.d.) on screen, in a vertical or horizontal direction, in order to access webpage content that falls outside of the viewable space contained on a device's display screen.

To test whether scrolling was enabled the library homepage URL for each of the 29 higher education libraries was manually entered into the default web browser installed on the iPod Touch. Figure 9 shows that whilst horizontal scrolling is enabled for one higher education library homepage, vertical scrolling on a mobile device is a prominent feature of 52\% of library homepages. Examples of vertical scrolling have been included below (see Figure 10):

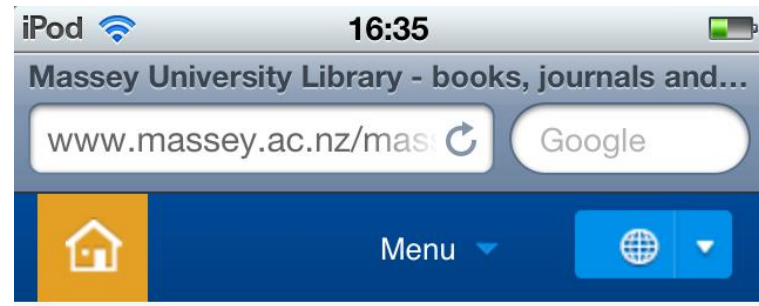

\section{MASSEY UNIVERSITY}

TE KUNENGA KI PŪREHUROA

UNIVERSITY OF NEW ZEALAND

Search all Massey websites

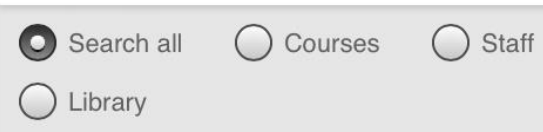

Home $>$ Research > Library

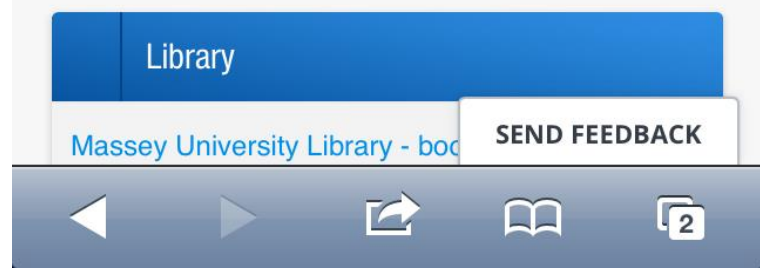

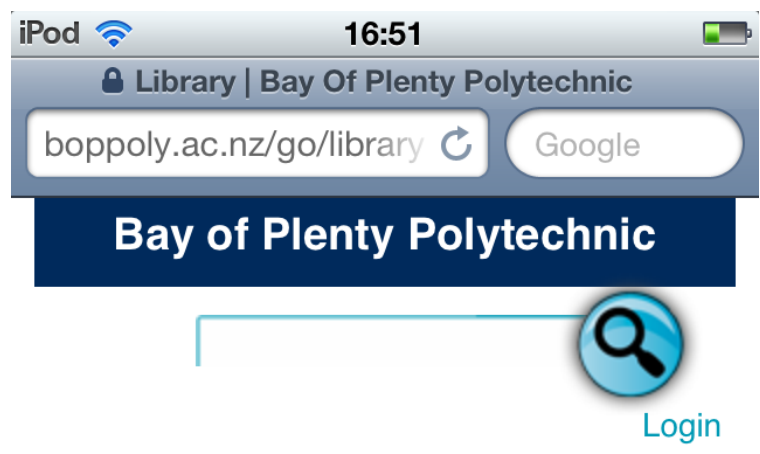

○ Information for you

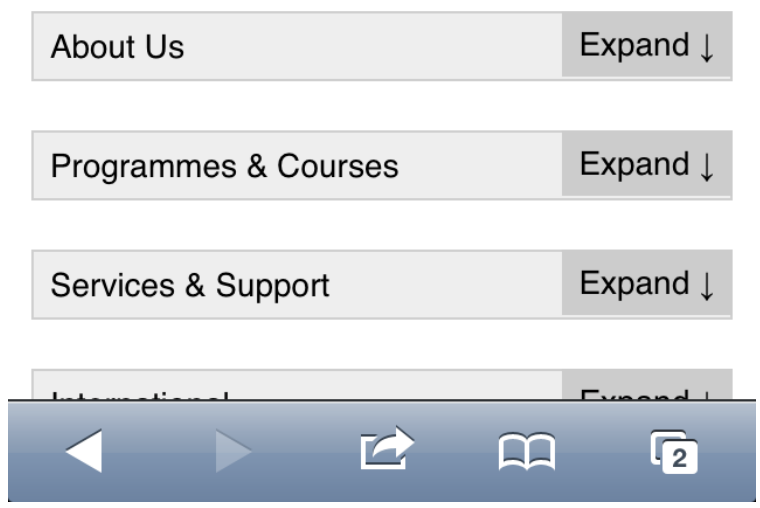

Figure 10: Massey University \& Bay of Plenty Polytechnic Library Homepages (mobile web) - rendered on iPod Touch

Interestingly, of the 14 libraries that did not use either the vertical or horizontal scroll in the design of their library homepage, only the Auckland University of Technology (AUT) Library provided content that was easily readable for the mobile environment (see Figure 11). 
AUT Library was also the only institute that offered a mobile URL redirect (m.aut.ac.nz/library) after manually entering the standard library URL into the mobile web browser on both the iPod Touch and Samsung Galaxy Gio devices.

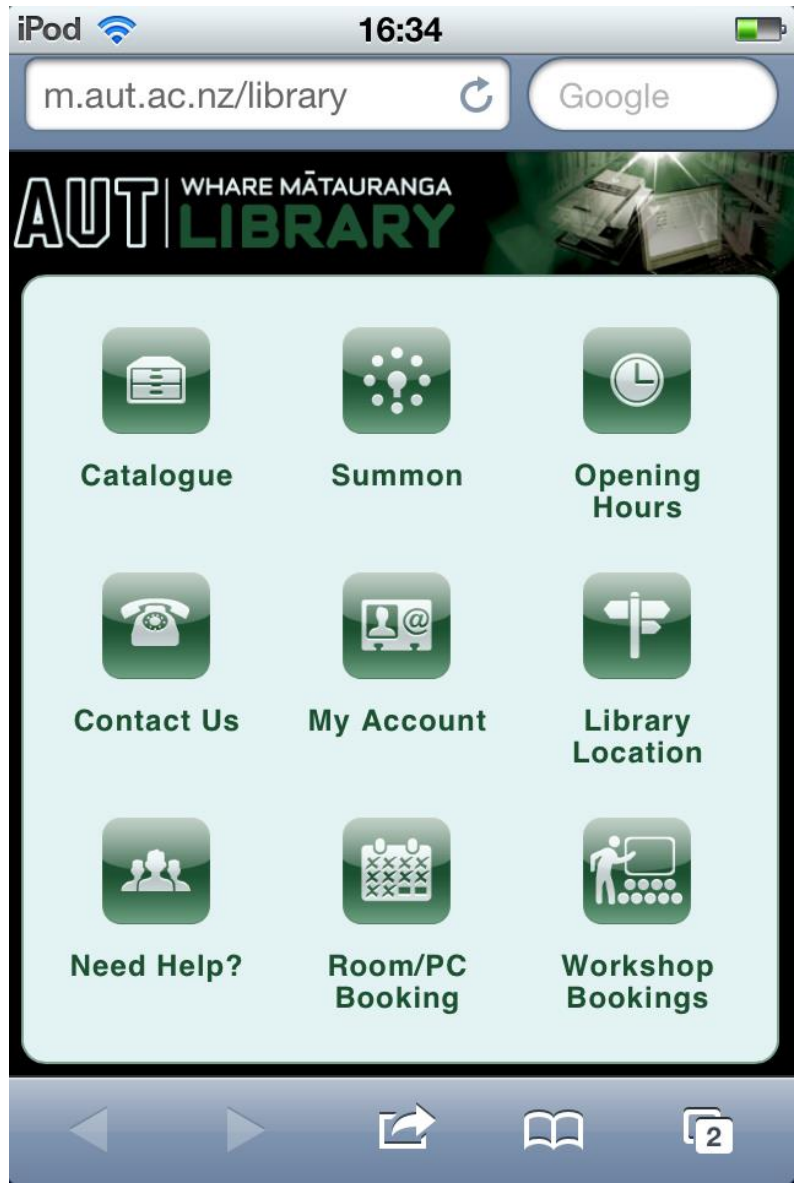

Figure 11: AUT Library Homepage - rendered on iPod Touch 


\subsection{Library Staff}

\subsubsection{Research Question 2: What impact, if any, do mobile technologies have on the}

professional development needs of higher education librarians?

To address the second research question, a survey questionnaire was distributed to the Library Managers of each of the 29 higher education libraries. In addition, the survey questionnaire was posted to three New Zealand listservs: NZ-Libs, Tel-Sig and TRW-General. To qualify to participate, respondents were required to be employed at one of 29 named higher education libraries, and hold a primary role of information literacy support, technical/CMS support, or IT support. Of the 88 individuals who applied, a total of 56 respondents qualified for participation in this research.

Part A:

What is your main role within the library? $(\mathrm{n}=56)$

\section{What is your main role in the library?}

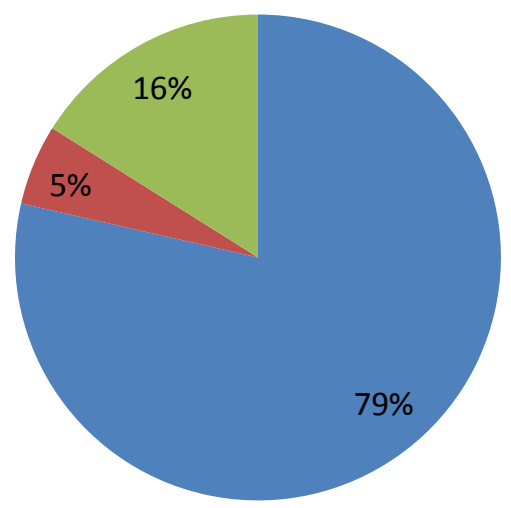

- Information Literacy Support

IT Support

Technical / CMS Support

Figure 12: What is your main role in the library?

The largest group of respondents that completed the online questionnaire were those library staff providing an information literacy support role. The second largest group was comprised of technical / CMS support staff with 3 respondents identified their role as providing IT support (see Figure 12). 


\section{Part B:}

Please state the level to which you agree or disagree with the following statements related to your perceptions of mobile technology? $(n=56)$

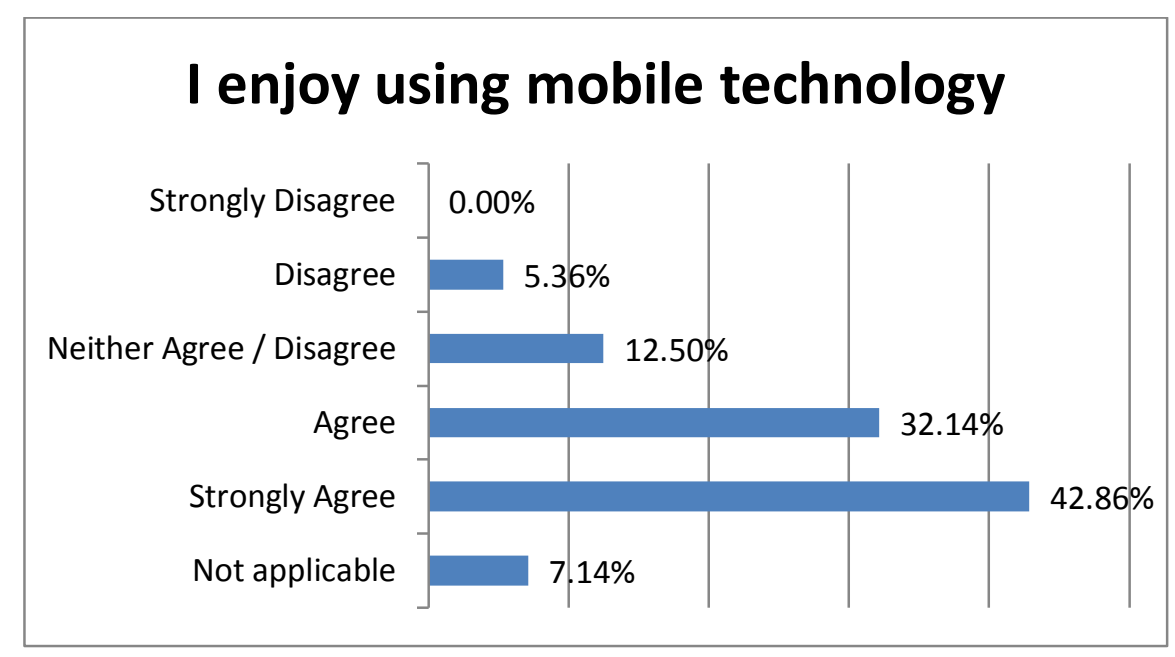

Figure 13: I enjoy using mobile technology

Figure 13 shows $50 \%$ of respondents agreed, or strongly agreed with the statement that they enjoy using mobile technology, with $78.57 \%$ of respondents indicating they have used a mobile app (see Figure 14).

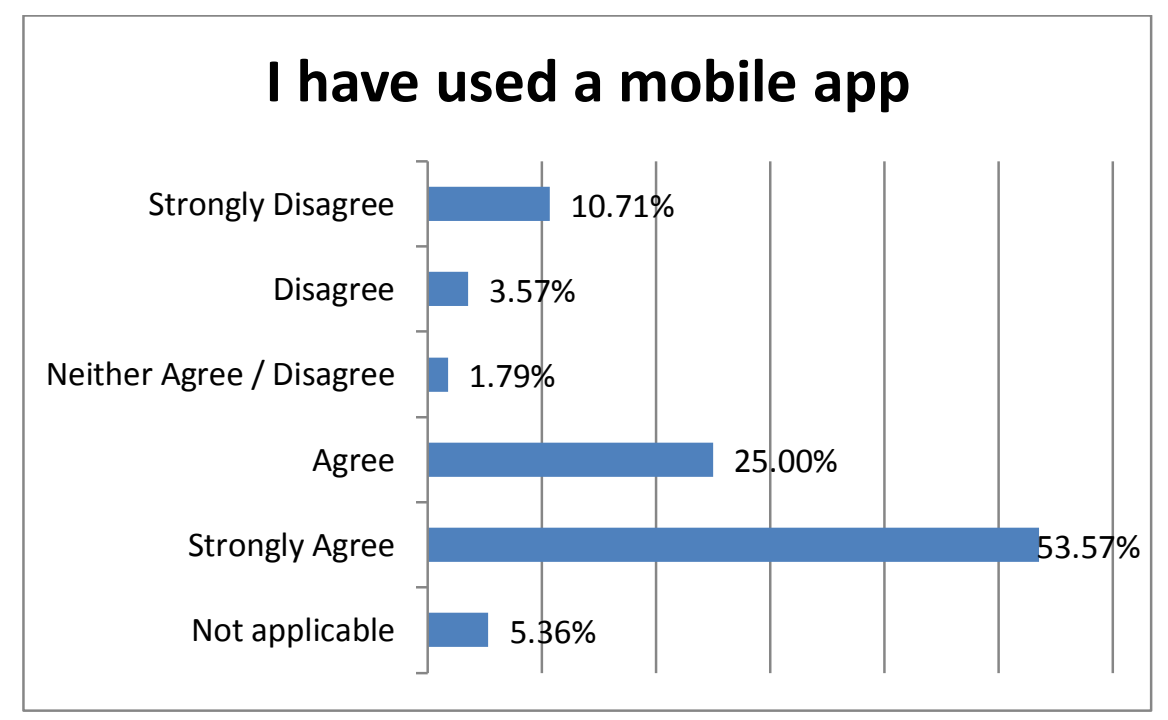

Figure 14: I have used a mobile app 


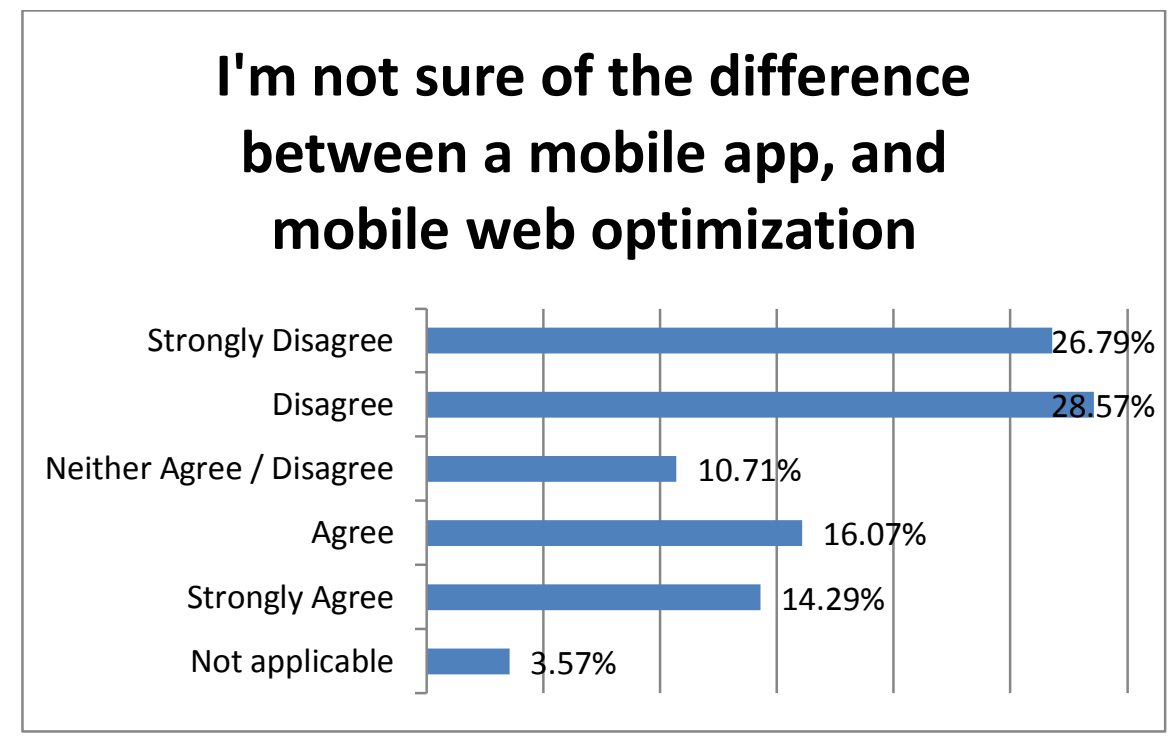

Figure 15: I'm not sure of the difference between a mobile app, and mobile web optimization

Over half of the respondents stated they were aware of the difference between a mobile app and mobile web optimization (see Figure 15).

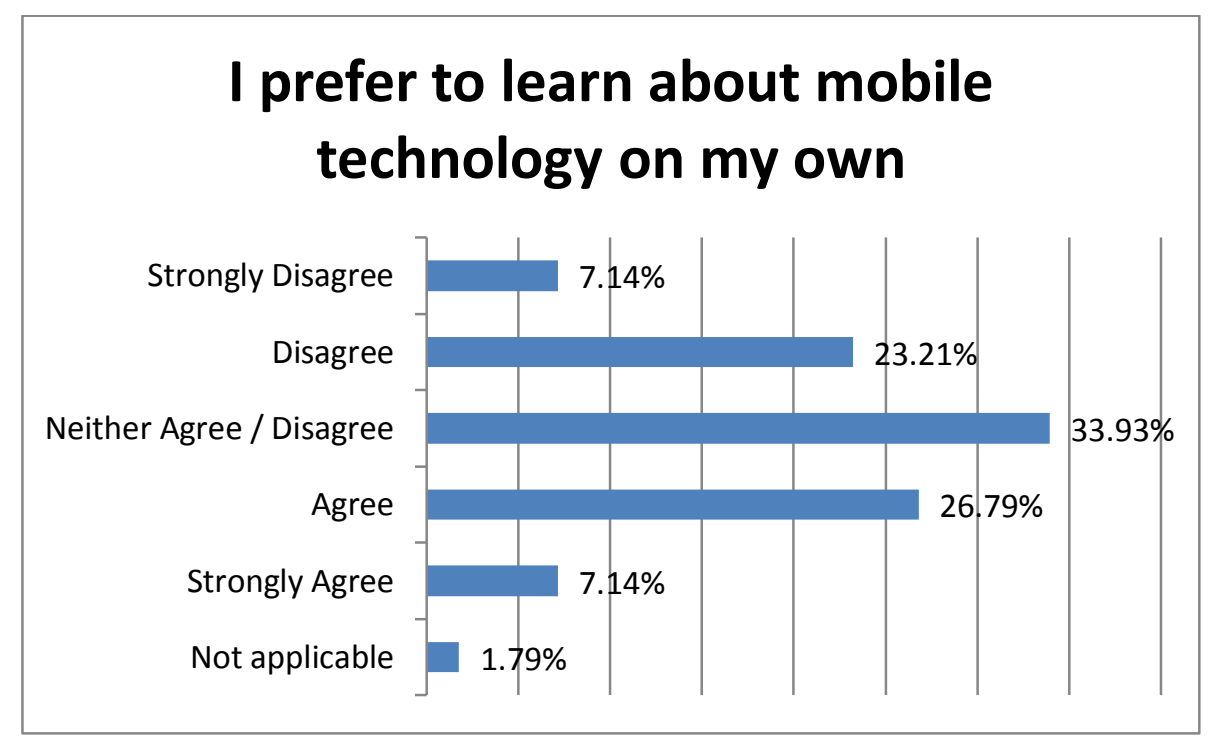

Figure 16: I prefer to learn about mobile technology on my own

Figure 16 shows that although $30.35 \%$ of respondents preferred to learn about mobile technology from others, a similar number of respondents (33.93\%) preferred to learn about these technologies on their own. 


\section{I prefer someone shows me how to use mobile technology}

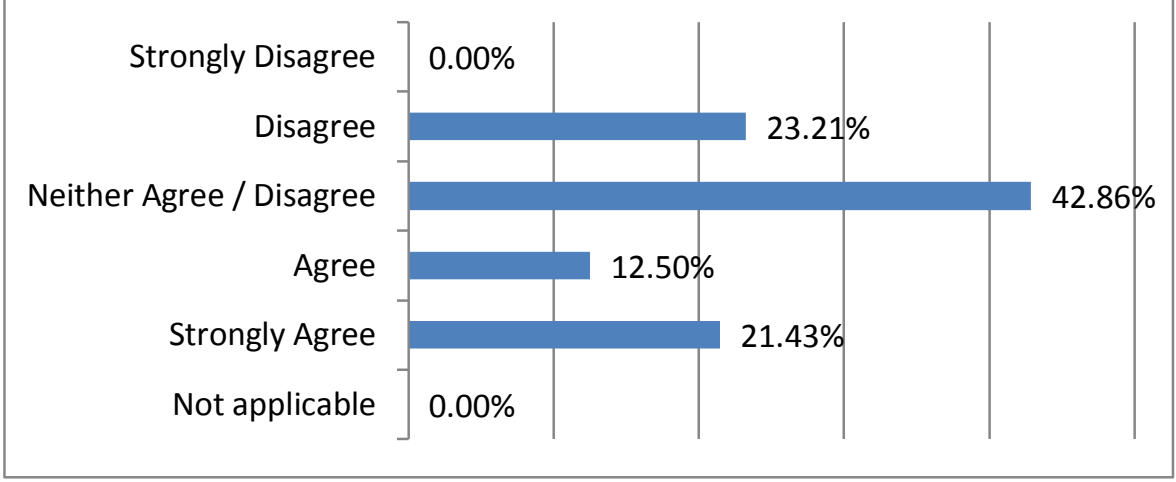

Figure 17: I prefer someone shows me how to use mobile technology

Figure 17 shows over a third of respondents would prefer to be shown how to use mobile technology, rather than learn on their own, with over half of the respondents indicating they are more likely to try mobile technology if recommended by a friend or family member (see Figure 18).

\section{I am more likely to try mobile technology if recommended by a friend or family member}

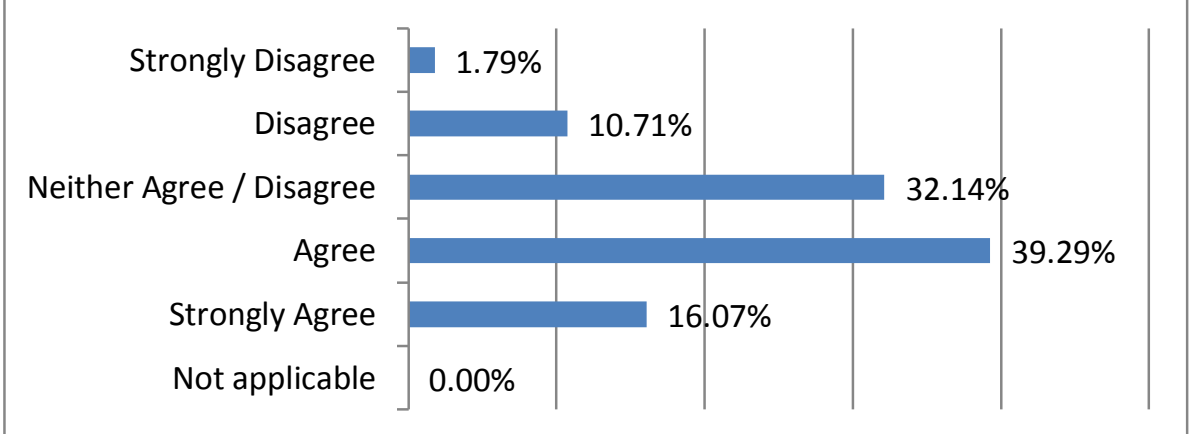

Figure 18: I am more likely to try mobile technology if recommended by a friend or family member

In summary, over three quarters of respondents had used a mobile app, with half the respondents indicating that they enjoyed using mobile technology. Over half of the respondents were aware of the difference between a mobile app, and a webpage optimised for viewing on a mobile device. Respondents were equally ambivalent towards learning about mobile technology on their own; however a third of respondents subsequently indicated they would prefer to be shown how to use mobile technology. Over half of respondents indicated they were more likely to try mobile technology upon the recommendation from a friend or family member. 
Please state the level to which you agree or disagree with the following statements related to mobile technology use within your library: $(n=54)$

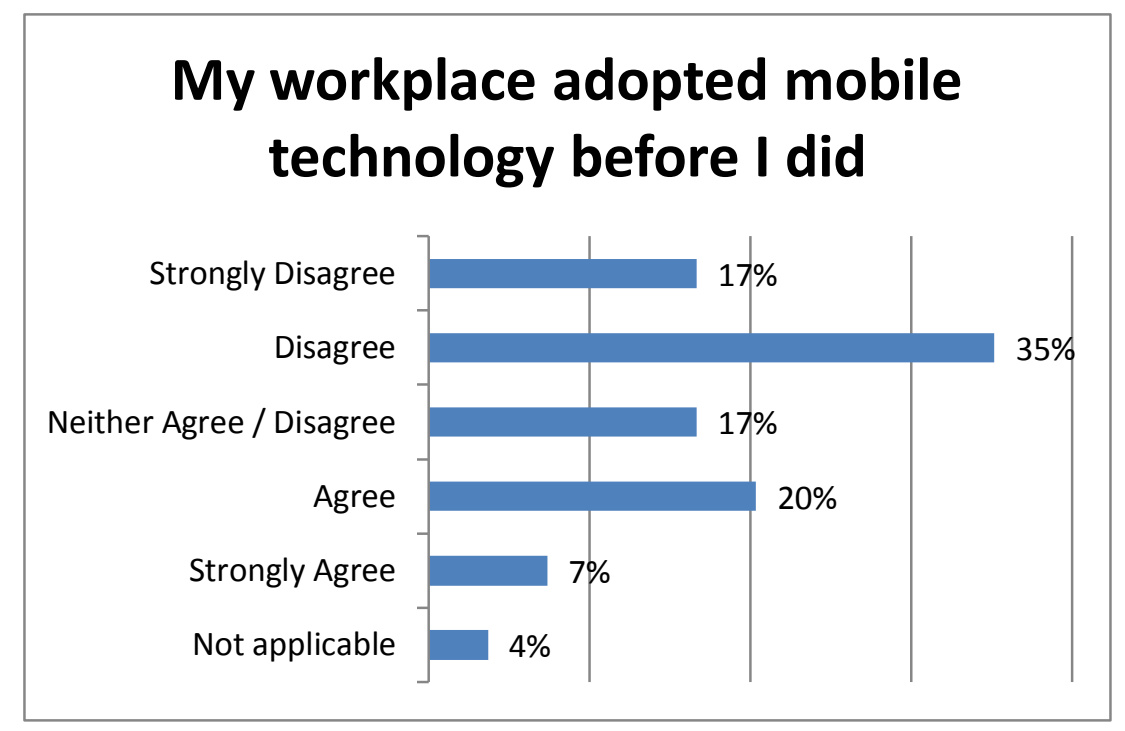

Figure 19: My workplace adopted mobile technology before I did

Over half of the respondents (52\%) indicated they had adopted mobile technology before their workplace had (see Figure 19), though surprisingly 54\% indicated they were required to learn about mobile technology as part of their work (see Figure 20).

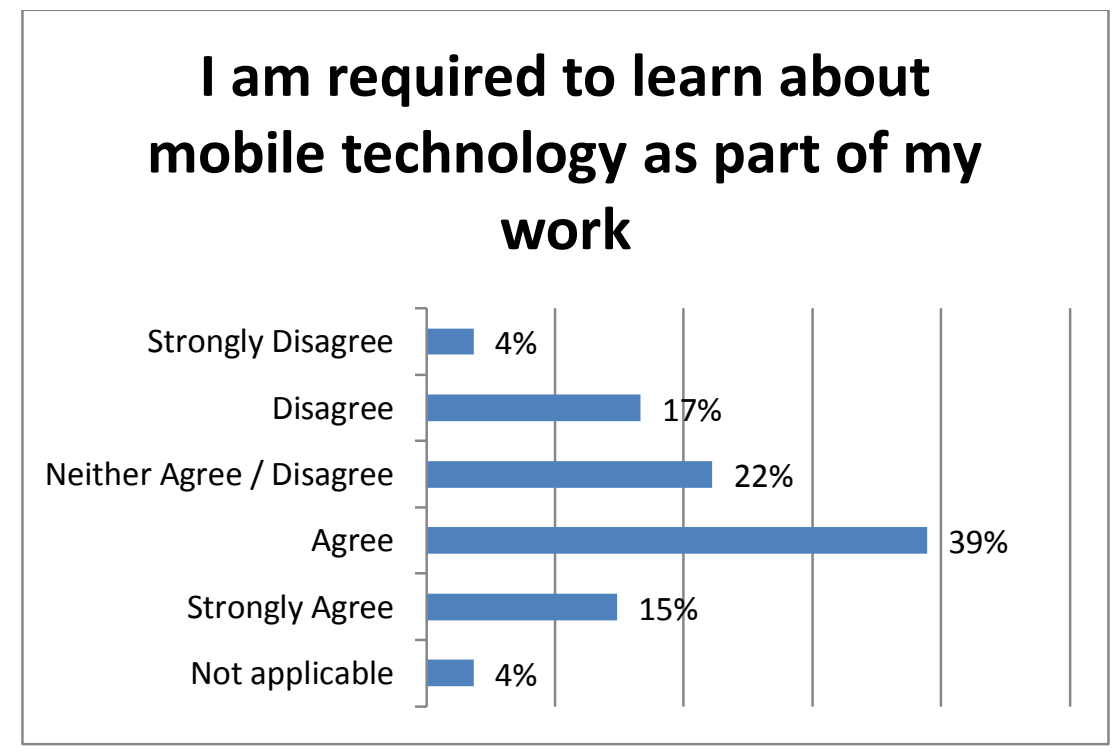

Figure 20: I am required to learn about mobile technology as part of my work 


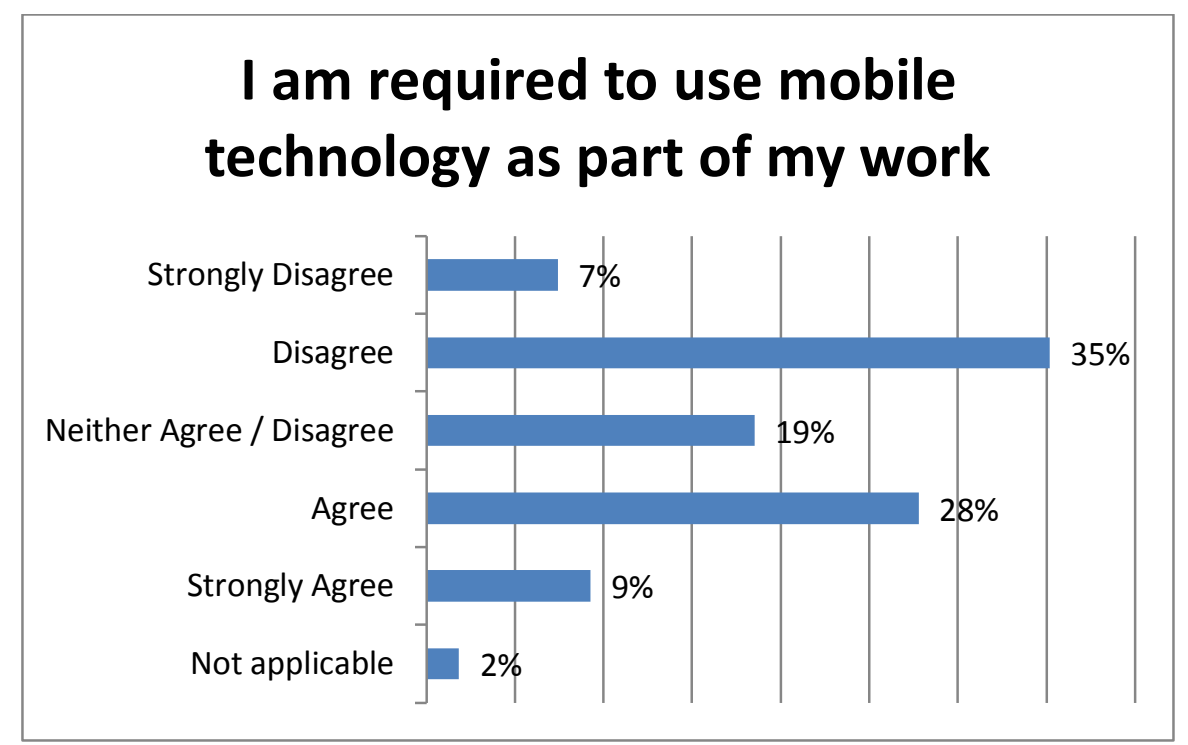

Figure 21: I am required to use mobile technology as part of my work

Despite the fact that $42 \%$ of respondents indicated that they were not required to use mobile technology as part of their work (see Figure 21), $69 \%$ of respondents indicated that they would like to see more opportunities to utilise mobile technologies within their own work (see Figure 22).

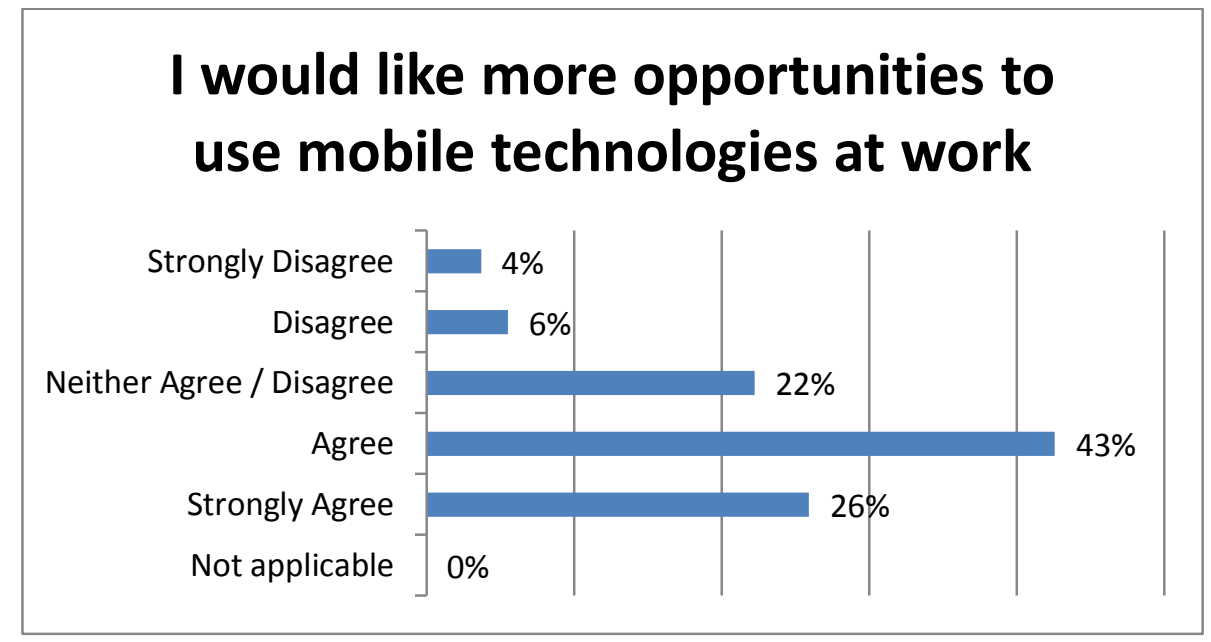

Figure 22: I would like more opportunities to use mobile technologies at work 


\section{My workplace supports the use of mobile technologies}

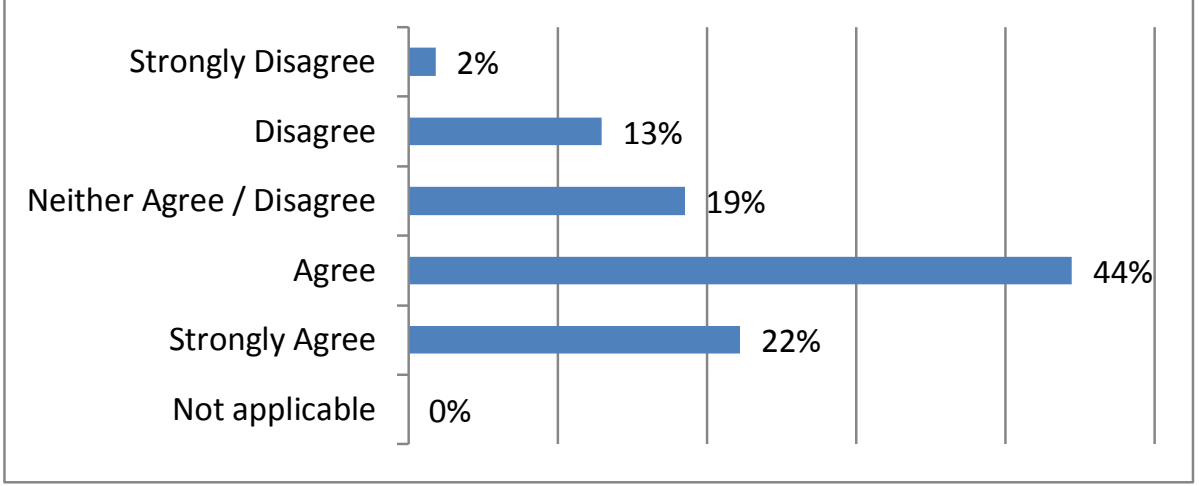

Figure 23: My workplace supports the use of mobile technologies

Figure 23 shows two thirds of respondents felt their workplace supported the use of mobile technologies with over half of the respondents (54\%) indicating they support others to use mobile technologies at work (see Figure 24).

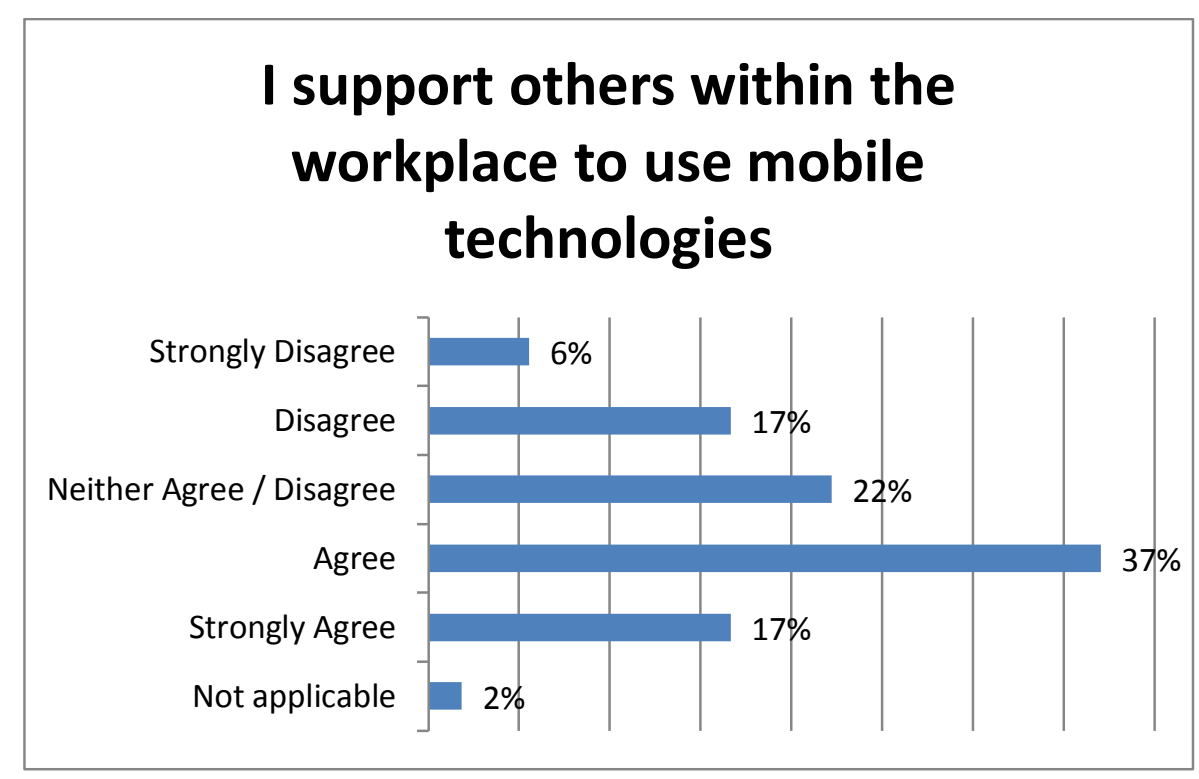

Figure 24: I support others within the workplace to use mobile technologies 


\section{The use of mobile technologies is compatible with my library's culture and values}

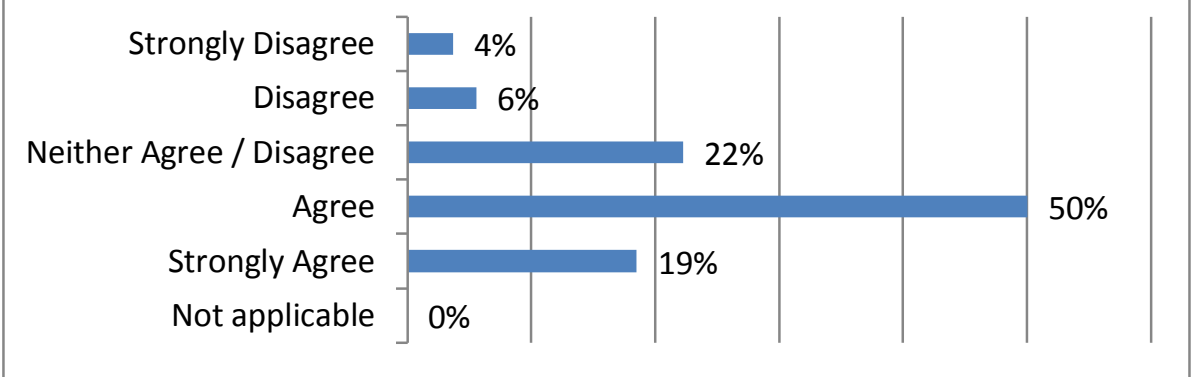

Figure 25: The use of mobile technologies is compatible with my library's culture and values

Nearly $70 \%$ of respondents identified that the use of mobile technologies was compatible with their library's culture and values (see Figure 25) with $85 \%$ of respondents indicating that the use of mobile technologies would better meet the needs of their library's customers (see Figure 26).

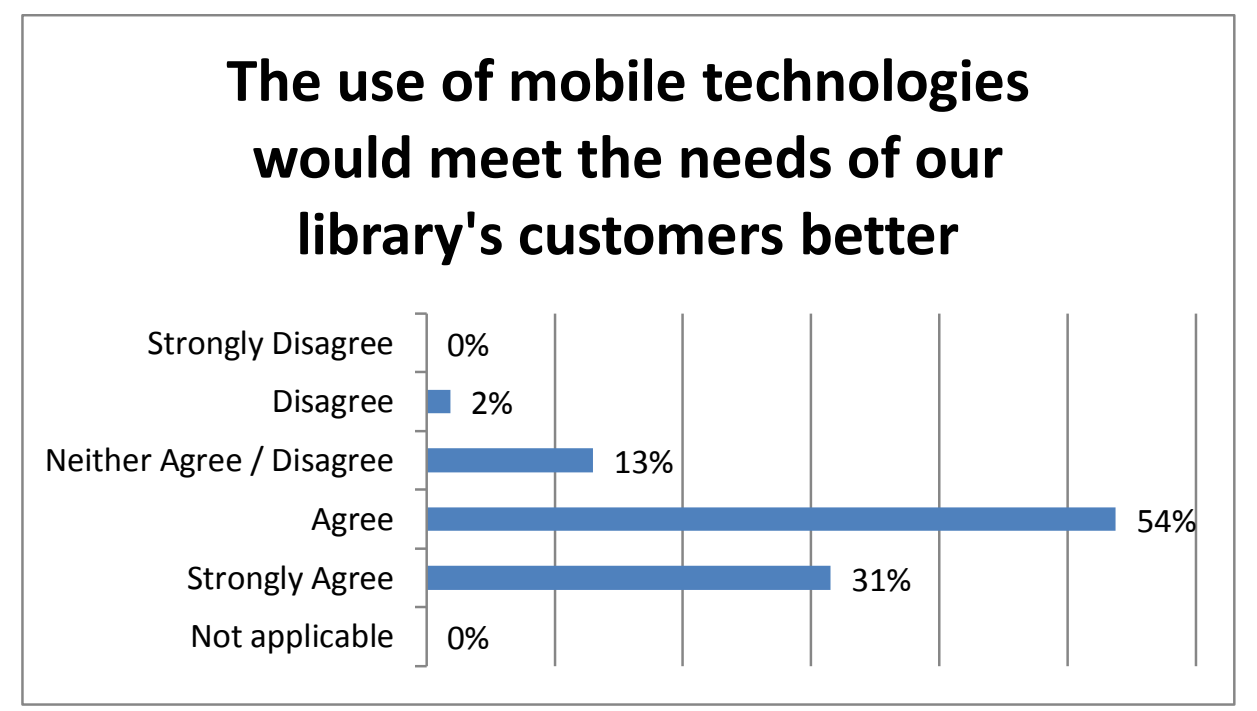

Figure 26: The use of mobile technologies would meet the needs of our library's customers better

In summary, over half of respondents indicated they had adopted mobile technology before their workplace. The same number of respondents also indicated they were required to learn about mobile technology in the course of their employment whilst just over a third of respondents indicated they were required to use mobile technology within the workplace. Over two-thirds of respondents indicated they would like to see more opportunities to utilise mobile technologies within their own work, with over half of the respondents stating they support others to use mobile technology. Two thirds of respondents felt their workplace supported the use of mobile technologies 
and the same number of respondents agreed the use of mobile technologies was compatible with their library's culture and values. A larger number of respondents, over three quarters, agreed that mobile technologies better supported the needs of their library's customers.

\section{Part D:}

To your knowledge, does your library provide a mobile app to access library resources? $(n=54)$

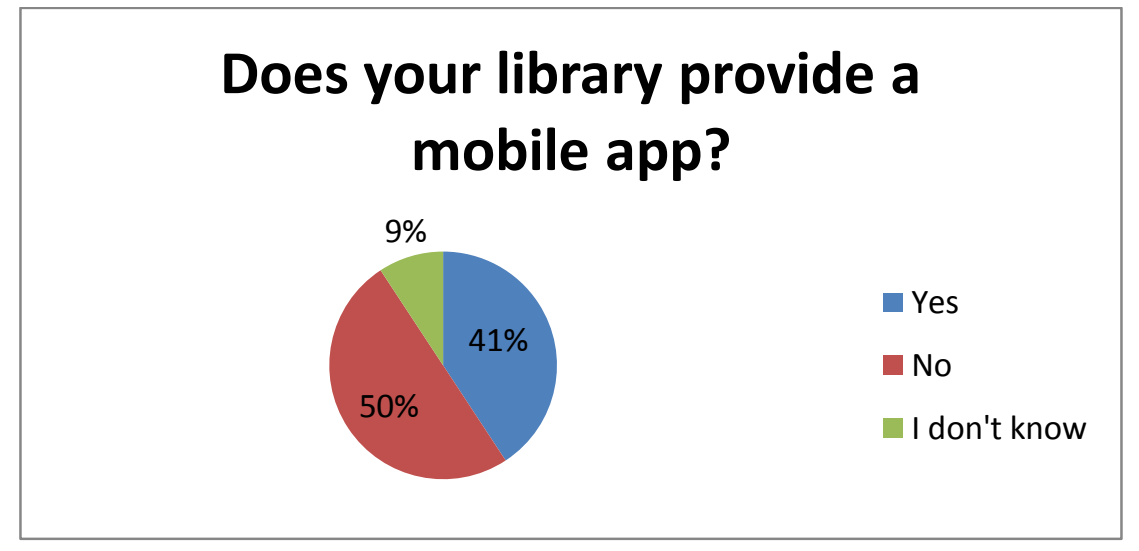

Figure 27: Does your library provide a mobile app?

Despite half of the respondents being aware their library provided a mobile app (see Figure 27) 32\% of these respondents indicated that they do not promote it (see Figure 29). The library app for The University of Auckland Library and Massey University Library are below (Figure 28).

\begin{tabular}{|c|c|c|}
\hline \multicolumn{3}{|c|}{ UoA Library } \\
\hline \multicolumn{3}{|c|}{ The University of Auckland Librar (6) } \\
\hline & $\begin{array}{l}\text { The University of } \\
\text { Auckland Library } \\
\text { In your pocket! }\end{array}$ & \\
\hline & $\begin{array}{l}\text { Library Catalogue } \\
\text { search the stacks }\end{array}$ & $>$ \\
\hline & $\begin{array}{l}\text { Articles \& more } \\
\text { search over } 150 \text { million } \\
\text { scholarly articles }\end{array}$ & $>$ \\
\hline & $\begin{array}{l}\text { My Library Account } \\
\text { renew items, check due } \\
\text { dates... }\end{array}$ & $>$ \\
\hline$=$ & $\begin{array}{l}\text { Book a PC } \\
\text { in the Kate Edger } \\
\text { Information Commons }\end{array}$ & $>$ \\
\hline है & $\begin{array}{l}\text { New Books } \\
\text { books recently added to } \\
\text { the Library collections }\end{array}$ & $>$ \\
\hline 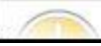 & Librarv Hours & \\
\hline
\end{tabular}

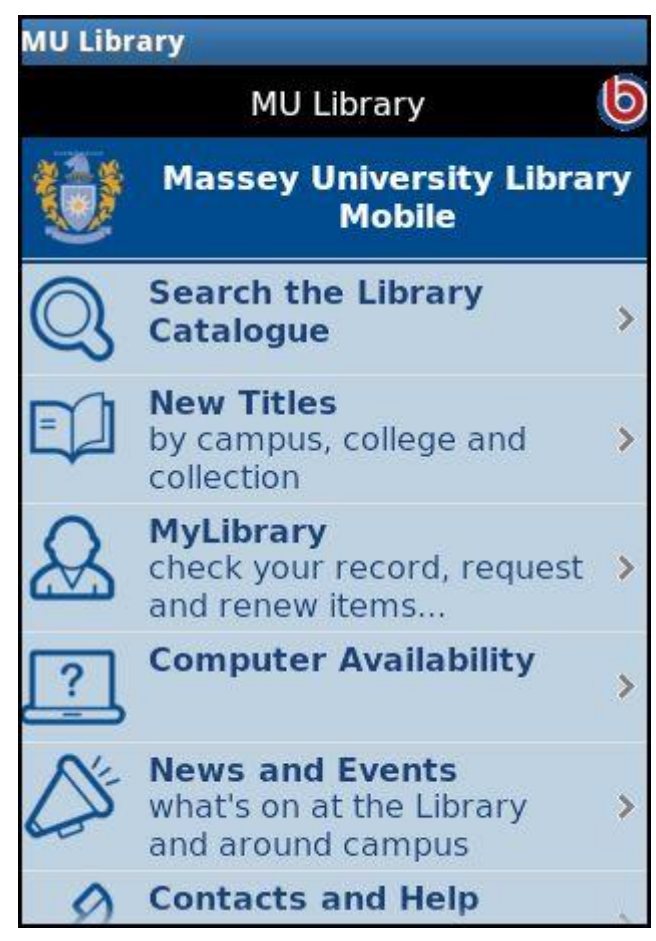

Figure 28: Library App for University of Auckland \& Massey University Libraries - rendered on Samsung Galaxy Gio 
Figure 29 also shows that respondents rely heavily on the website and social media as a means to promote their library app.

Please indicate the ways in which you promote your library's mobile app? $(n=22)$

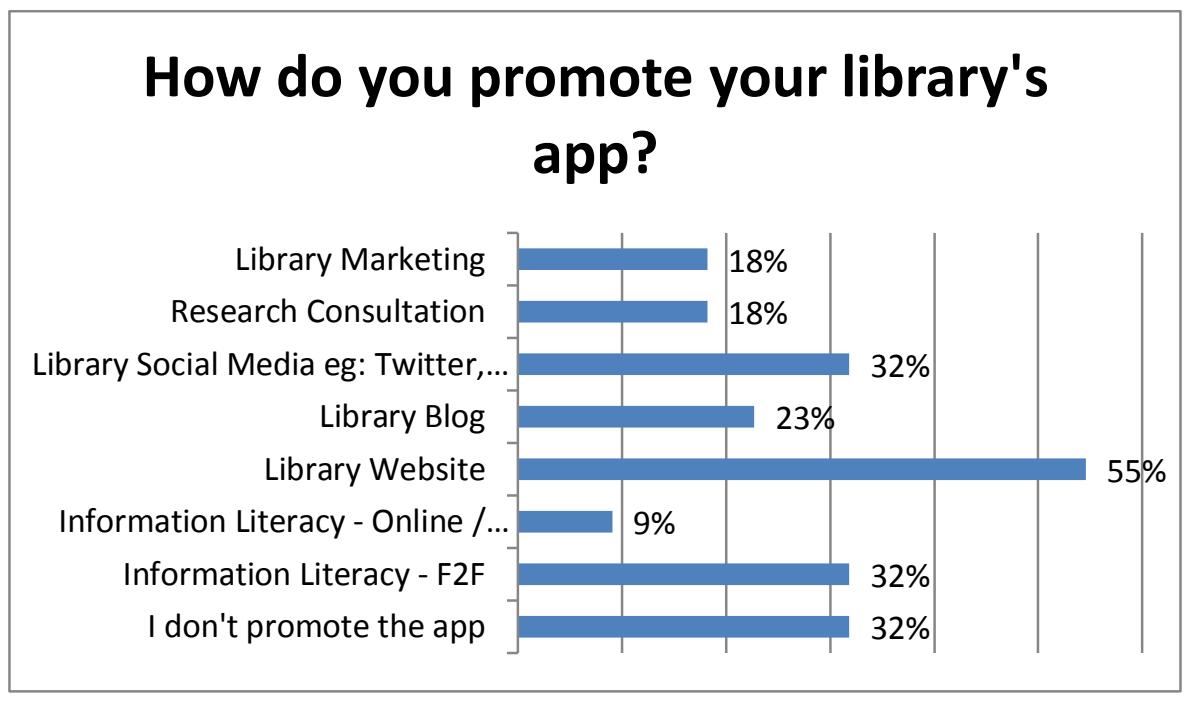

Figure 29: How do you promote your library's app?

Support within the Communication Channel (Rogers, 2003, p.18) emerged as a major theme from the library marketing comments (see Figure 29) provided by three respondents.

"I am unsure about the ways in which it is promoted"

"Slideshow ... constantly running on a public screen"

"Promote the library's mobile app during faculty's staff meeting"

Comments from the first respondent suggest there is a disconnect within the communication channel; the respondent is aware library marketing is employed to promote a new innovation (library app) although the process by which this may occur appears not to have diffused to all members within this particular social system. In contrast, comments from the second and third respondent highlight the simplicity of communicating a new idea using repetitive graphical/visual displays and face-to-face engagement with peers. 


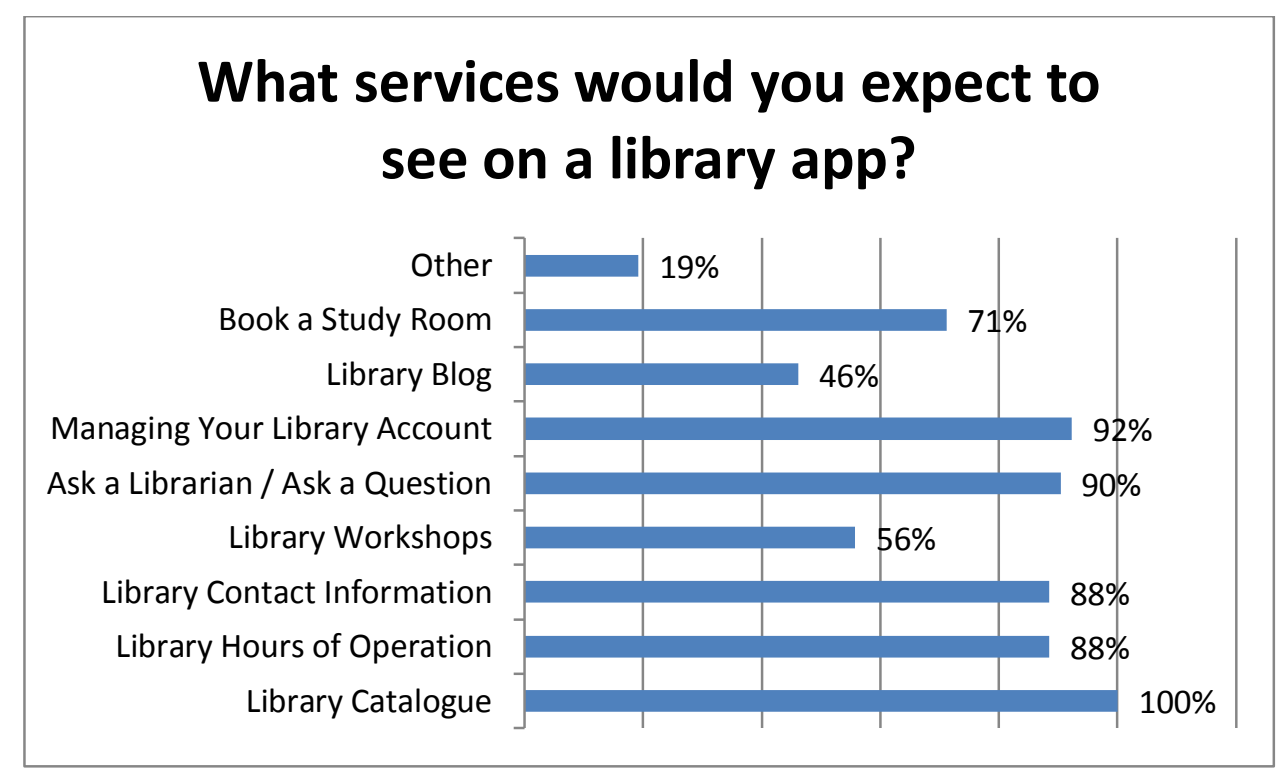

Figure 30: What services would you expect to see on a library app?

In describing what other services would be useful on a library app (Figure 30), two specific service areas emerged from respondent comments: Advanced Library Services and Campus Specific Services.

Respondents commented that Advanced Library Services should include the provision of access to help guides and subject portals, full search functionality within both the library catalogue and major databases and the ability to chat with a librarian online.

Respondents' comments regarding Campus Specific Services included the provision of wider-campus information within a library app. Specific suggestions included bus timetables and campus maps. One respondent suggested that including access to supplementary learning support services would also be a valuable function for a library app.

Whilst recent studies indicate a preference for graphical location-based information, such as a library floor plan, as a desirable element to access within a library's mobile environment (Bridges, Rempel, \& Griggs, 2010, p.314; Paterson \& Low, 2011, p.418), it is important to balance content with context in the development of a library app. 
How might you promote a library mobile app to staff and students within the library?

Support within the Communication Channel again emerged as a major theme within this section of the research (Rogers, 2003, p.18) and five marketing areas were identified: Continuation of traditional library marketing, Maximising Teaching Moments, Promotion of library services within the virtual library environment, Utilising new technology platforms for marketing and Non-promotion of an existing library app.

A number of respondents suggested the continuation of traditional library marketing would be valuable in promoting a library app. Specific suggestions included featuring the library app within library displays (including digital presentations on an LCD display and static displays), promoting the app through staff and student newsletters (or pānui), through discussion at staff meetings or following karakia (prayer).

Suggestions for maximising teaching moments include the provision of print-based handouts, and face to face promotion with students at the service desk. It was also suggested that teaching moments be applied during library orientation classes, library tours, and at curriculum-specific information literacy classes.

Suggestions for the promotion of library services within the virtual library environment included promoting the library app through the library website, through direct email or library blog postings.

In utilising new technology platforms for marketing, respondents suggested the library app could be promoted successfully via social media platforms such as Facebook and Twitter, and through the promotion of $Q R$ codes. Four respondents subsequently offered their own views on how they thought the library app could be marketed to specific stakeholder groups:

"Tout it as the 'anywhere library' ... access on the bus etc"

"Choose the target audience - distance (or) part time ... always on the go"

"(It's a) library in your pocket ... take the library with you"

"Use of a mobile phone as an aid to find items on the shelves" 
Respondents' comments from the data findings related to the Non-promotion of an existing library app have been included below:

"There doesn't appear to be much of a drive to promote our app - it kind of gets forgotten about..."

"At the moment, it (the library app) is buried several clicks away from our front page of the website. If it's on the front page, then it's more obvious ... and if staff were encouraged to use it more, then they would feel more comfortable promoting it ... "

“Promoting our library app doesn't seem to be an important thing to do. We promote the library homepage more as a one-stop-shop probably because it links to lots of other information that isn't on the app like databases and subject guides"

These comments suggest that the library app may no longer be considered an innovation to all units contained within a social system, specifically the unit of library staff. However if consideration is given to other interrelated units contained within the social system (Rogers, 2003, p.23), such as academic staff and learners', one or more of the following issues may be present for those higher education libraries that currently use a library app:

1. A formal marketing plan to promote the library app may not exist or is not known to library staff involved in front line service

2. The placement of the library app may not coincide with a library user's typical navigation of the library website

3. Library staff do not feel supported to learn mobile app technology nor are they confident in promoting mobile app technology to others

4. The library app, in its current form, may not fulfil the needs or expectations of all its library users', nor does it mirror the functionalities currently available on a web-based platform

Following on from the issues identified in 3 above, one respondent suggested that in order to successfully communicate (promote) an innovation (library app), providing education or professional development training to library staff, in conjunction with access to mobile technology devices, is required: 
"First of all, you have to train the library staff and give them devices to use. Only then can we demonstrate / promote (the library app) to staff and students"

The respondent's comment highlights the importance by library staff to have adequate access to resources, and time to explore the benefits of an innovation, during the diffusion process (King, 2001, p.12; Rogers, 2003, p.20).

Why do you think your library decided not to adopt a library mobile app?

Three trends that emerged from respondent comments in this section of the research were: Financial cost, Lack of resources and a Preference for a mobile web experience.

Seven respondents' noted that the high financial costs involved in mobile app design, development and implementation would be the most likely reason for their library not adopting a mobile app. Whilst one respondent commented:

"Senior management are unwilling to authorise purchase"

The respondent did not disclose the reason for the non-authorisation of the purchase.

In the trend lack of resources, two respondents noted higher priorities particularly post-earthquake were identifiable barriers to any mobile app development and implementation:

"There have been other priorities; it will happen soon"

"Other priorities post-earthquake"

Six respondents commented on their perceived advantages of the mobile web over the mobile app as reasons for their library's possible non-adoption of a library app, suggesting that over time, one or more units within the social system have rejected one innovation (mobile app) in favour of perceived benefits gained from a new innovation (mobile web):

"We provide a library website optimised for mobile devices, rather than an app. We find this works better as it does not require anybody to download anything" 
"Implementation difficulties; fragmentation between mobile devices (Android/iOS).

Maintenace - mobile OSs constantly update often breaking existing functionality"

"I think we felt that being able to access the library's Webpage using a mobile phone web browser would be sufficient"

"Some people argue that there is a movement away from apps as mobile websites basically do the same thing"

"We have developed browser based apps, but we are looking at more holistic approach to layout and design so there is no need for splitting development streams and supporting multiple code bases. It is better to create a responsive design which will work on any browser than an app that on the whole sacrifices a heap of functionality"

"We didn't specifically decide not to; more that we haven't decided *to*. / / --That said, I would decide not to (in favour of a mobile web interface) because with mobile apps you have to create one per type of device and keep them constantly up-to-date: way too much maintenance work" 


\section{Part E:}

To your knowledge, does your library's website provide a mobile web interface that permits easy access to library resources on a tablet or smartphone? $(n=51)$

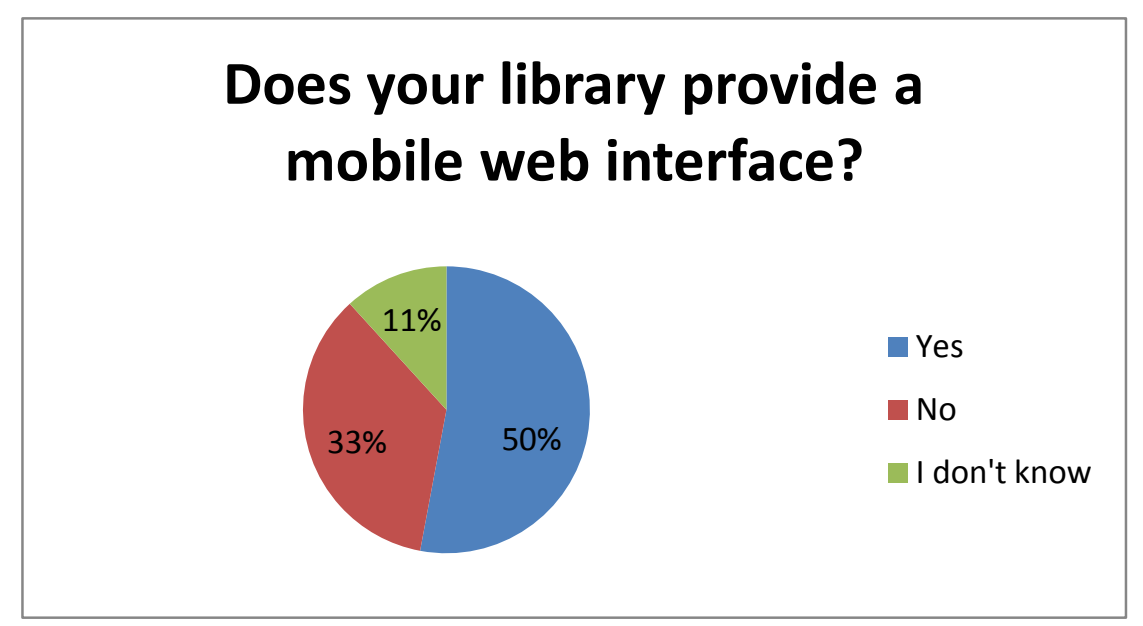

Figure 31: Does your library provide a mobile web interface?

Whilst half of respondents acknowledged their library provides a mobile web interface (see Figure 31), almost a third of these respondents were not able to identify one or more library pages that had been optimised for the mobile web environment (see Figure 32).

Please indicate which of your library webpages are optimised for use on a mobile device $(n=26)$

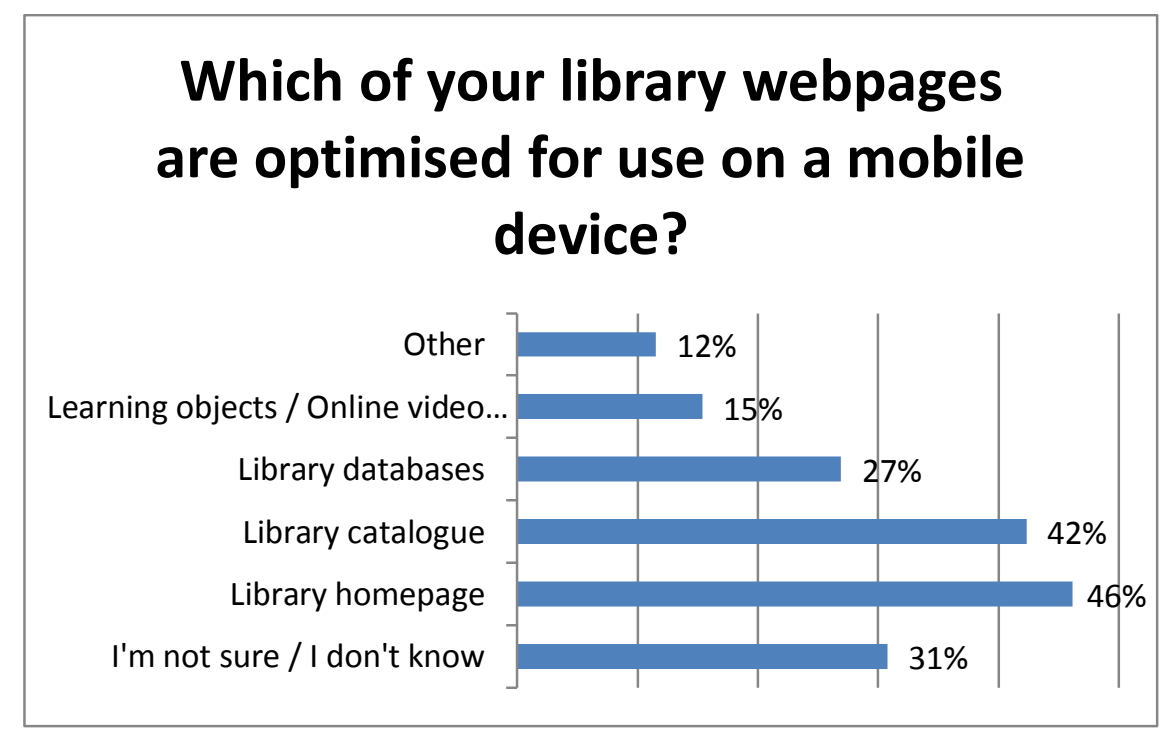

Figure 32: Which of your library webpages are optimised for use on a mobile device? 


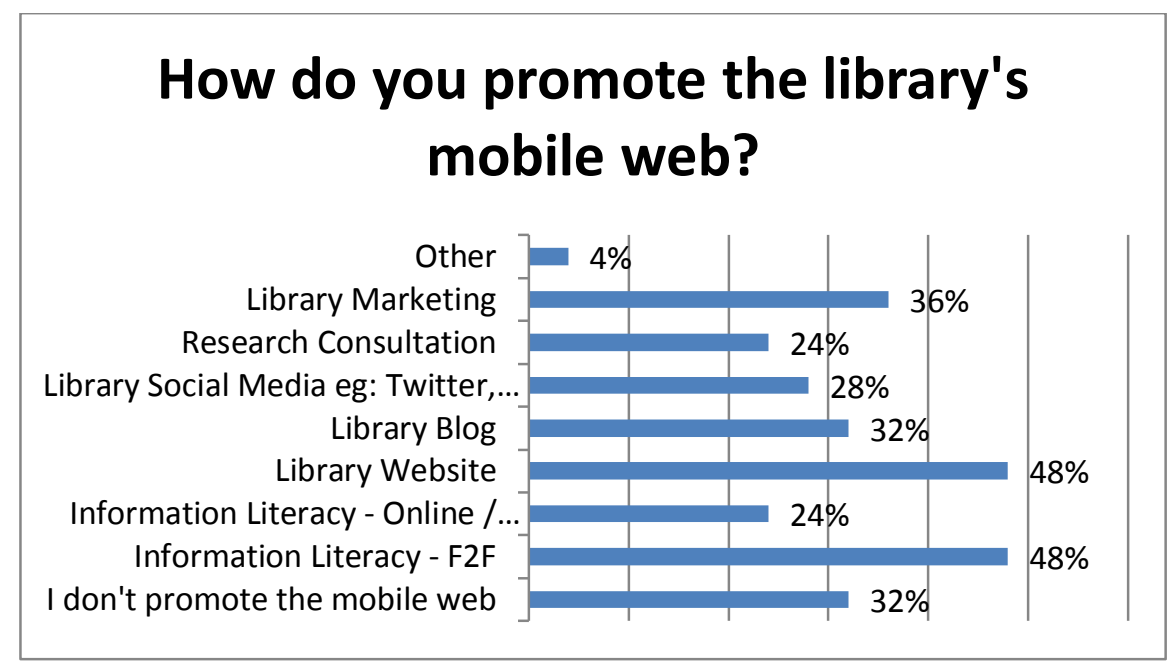

Figure 33: How do you promote the library's mobile web?

As with the mobile app, almost a third of respondents indicated they do not promote the mobile web (see Figure 33) with almost half of respondents indicating they are most likely to promote the mobile web via the library website, or during face to face information literacy interactions.

What library services would you expect to see optimised for the mobile web? $(n=52)$

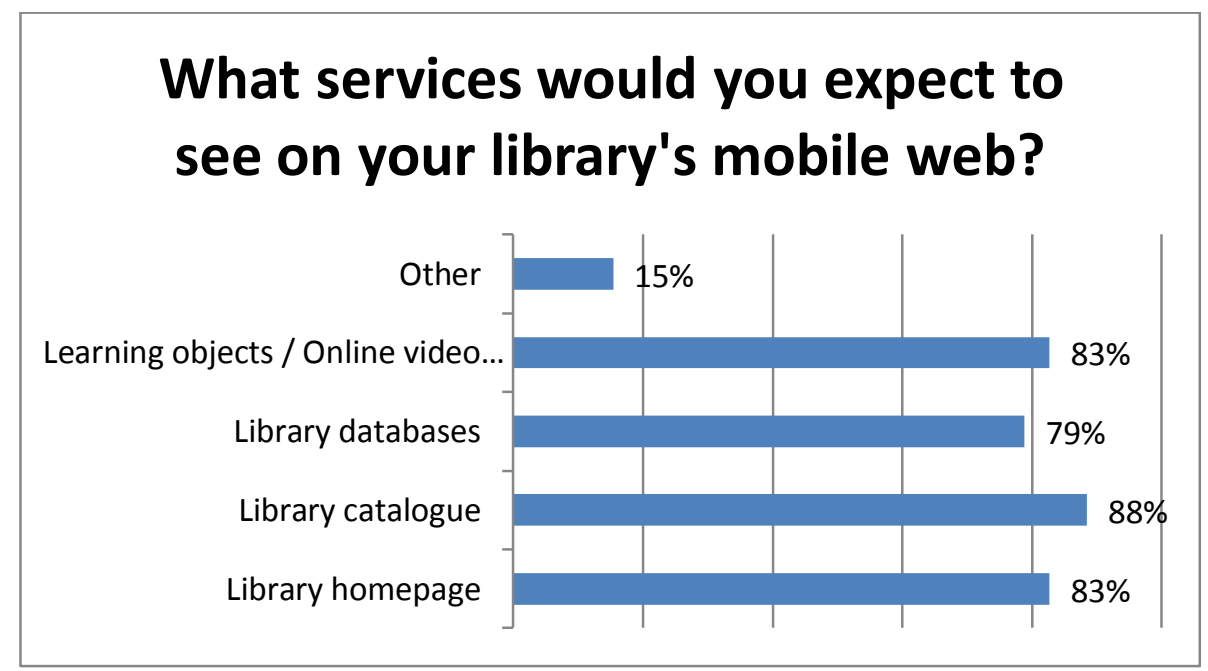

Figure 34: What services would you expect to see on your library's mobile web?

Mobile optimisation of the library catalogue (88\%) rated highest amongst respondents, followed equally by the library homepage and databases (83\%) (see Figure 34). Additional comments from respondents' suggested the inclusion of the following services: library contact information, facility to manage a library account, workshop information, and learning objects or tutorials. 
How might you promote your library's mobile web to staff and students within the library?

Similarly in promoting the library's mobile web, respondents again focused on the Communication Channel, and identified the same four areas as specified with promotion of the library app: Continuation of traditional library marketing, Maximising Teaching Moments, Promotion of library services within the virtual library environment and Utilising new technology platforms for marketing. A fifth area Discovery learning of the mobile web also emerged.

Within the area of continuation of traditional library marketing respondents additional suggestions include: word of mouth, library brochures, posters, bookmarks, and library launches.

Within the area maximising teaching moment's respondents specifically suggested the following additions: research consultations, tutorials and device demonstrations would maximise the promotion of mobile optimized webpages. One respondent suggested library staff create advocates for the mobile web by working intensively with one programme to gain support.

Within the area promotion of library services within the virtual library environment respondents added the following suggestions: promotion via the students' learning management system, for example, Moodle or Blackboard and adding information to staff email signatures and phone voicemail messages.

Within the area utilising new technology platforms for marketing the same promotional techniques were identified however there were no new suggestions offered by respondents.

Respondents' comments for the Discovery learning of the mobile web are included below:

"Automatic device detection (but overrideable). Use a standard subdomain name eg mobile.library.domain.ac.nz or m.library.domain.ac.nz"

"If it was functioning it would mean they could take the catalogue with them when they are searching the shelves for items"

"Shouldn't have to promote it so much as it should be experienced when users access the web environment via mobile device. In my experience/observation $\mathrm{pp} / \mathrm{w} / \mathrm{smart}$ phones/tablets use them without being pushed to for a wide range of everyday library 
interactions and not for others either because lack of functionality or because task is better performed at a desktop/laptop (e.g. writing an assignment vs browsing catalogue whilst amongst the shelves"

Why do you think your library decided not to adopt mobile web optimisation?

Likewise respondent comments in this section of the research mirror those for the library app and focus on the following two areas: Financial cost and Lack of resources. A Preference for a mobile web experience emerged as a third discussion point.

Three respondents' noted financial costs as the most likely reason for their library not adopting mobile web optimisation. Priorities over infrastructure related costs (post-earthquake) were also a likely reason for non-adoption.

Six respondents' noted a lack of resources impacted on mobile web development, specifically a lack of in-house skill for mobile web development and an awareness that staff abilities are not focused on technological development. One respondent's (below) supports the latter statement:

"Technical limitation in the capacity of the CMS chosen by the parent institution"

Within the theme preference for a mobile web experience, respondents offered the following comments:

"Again partly we just haven't decided *to* prioritise it over everything else on the to-do list. / ...Though we sort of have decided to prioritise it, but turns out we have even less control over our web content management system than over our catalogue, and campus IT's to-do list is even longer than ours. So it's not going to happen any time soon"

"It is in the process of doing so but has yet to be implemented"

"Our CMS is under review and mobile web optimization is one of the important criteria for the new CMS" 
Part F:

What is your gender? $(n=56)$

\section{Gender of Respondents}

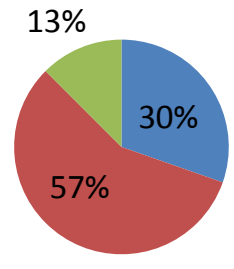

Figure 35: Gender of respondents

What is your age? $(n=56)$

\section{Age of Respondents}

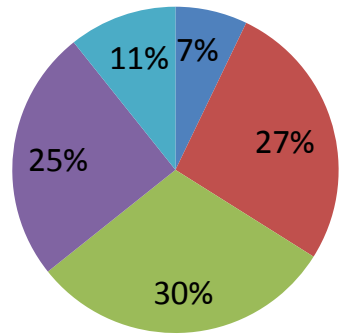

- 20-29

- 30-39

40-49

- Over 50

- Prefer not to answer

Figure 36: Age of respondents

Do you have any other comments regarding this survey?

Initial comments, directed at the researcher, focused on the technical issues of answering the survey questionnaire and highlighted testing of survey functions should have been more thorough.

Overall however, respondents commented that they felt the survey was relevant, timely and interesting. Additional comments have been included: 
"Suspect lot of library management expect staff to be up with play almost by osmosis. Concerted training needs to happen with all these techie devices if we are to be conversant with them"

"Our library has a dedicated person who looks after promotion of mobile library technologies, and it isn't my role to promote them"

"Made me re-visit my library's app"

"Interesting distinction to look at Mobile optimisation vs dedicated Mobile App. I tend to mix and match between both approaches in a given area in my own general mobile usage. Ideally maximising both approaches would be best but many resourcing factors come into play including speed of change etc..."

"It's a very current topic and the direction in which libraries should be going"

"It's a worthwhile survey to run \& I'll be interested to see the results. At my library we have dipped our toe in this particular water, but need to do much more"

"It is nice for the libraries to design mobile app as smartphones and tablets are now very popular"

"I am very interested in this area so I would like to see some results later if possible! / As eLearning Librarian I am very much promoting mobile usage. $i$ work on instructions for downloading ebooks onto tablets, the latest apps that are relevant to students/staff"

"...there is an institution wide community of practice that meets to discuss the latest innovations in mobile technology"

Key themes from respondents' comments suggest there is support and a desire for continued research into the use of mobile technologies in a higher education library environment. Whilst libraries are becoming more familiar with mobile technologies, library staff have signalled a need for additional professional development in this area. 


\section{CONCLUSION}

This research study has explored the extent to which Aotearoa New Zealand's higher education libraries are using mobile technologies for the delivery of its information and research services, and the impact these technologies have on the professional development needs of higher education library staff.

This research indicates that mobile apps have been developed, and are in fact used, by a small number of higher education libraries; however there appears to be a shortfall between services offered on a library app and the expectation of functionalities required to satisfy a user's needs. Further findings within this research suggest there is a growing preference to investigate and implement library services optimised for the mobile web.

Presently, the majority of web-based library homepages belonging to higher education libraries are content-heavy and not fit for purpose on a mobile platform. Barriers to the implementation of both a mobile app, and mobile web development, include a lack of resources and financial costs associated with design and development.

Findings suggest library staff are open to new innovations, including mobile technologies, though do not always feel supported to explore and develop these skills professionally within the workplace. The implications for this include a lack of confidence in promoting innovations to others, and a lack of awareness of innovations available to library users.

Suggestions for further research include an examination of mobile technologies in use by other types of libraries within Aotearoa New Zealand, and future researchers may consider replicating this research in a school or public library environment. Future researchers may also consider surveying library users to examine their perceptions and experiences of using mobile technologies and the impact or effect these may have on life-long learning. Research into the relationship between selfdirected and directed professional development for library staff and the rate of innovation adoption towards mobile technologies may also prove to be valuable for the future. 


\section{BIBLIOGRAPHY}

Apple Inc. (n.d.). iOS: The world's most advanced mobile operating system. Retrieved May 5, 2013, from http://www.apple.com/nz/ios/what-is/

Barnhart, F. D., \& Pierce, J. E. (2012). Becoming mobile: Reference in the ubiquitous library. Journal of Library Administration, 52(6-7), 559-570.

Barthorpe, G. (2012). Are we there yet? Do we have the staff we need to meet the needs of new generation learners? Paper presented at the Proceedings of the 2012 IATUL Conferences, 47 June 2012. Retrieved from Purdue University Purdue e-Pubs: http://docs.lib.purdue.edu/cgi/viewcontent.cgi?article=1133\&context=iatul

Best Practices Working Group, \& W3C. (2008a). Mobile web best practices 1.0: Basic guidelines. Retrieved May 21, 2013, from http://www.w3.org/TR/mobile-bp/

Best Practices Working Group, \& W3C. (2008b). Mobile web best practices 1.0: Basic guidelines: Page Size Retrieved May 21, 2013, from http://www.w3.org/TR/mobile-bp/\#d0e1099

Best Practices Working Group, \& W3C. (2008c). W3C mobileOK basic tests 1.0: Conformance Retrieved May 21, 2013, from http://www.w3.org/TR/mobileOK-basic10tests/\#about the tests

Bolstad, R., Gilbert, J., McDowall, S., Bull, A., Boyd, S., \& Hipkins, R. (2012). Supporting futureoriented learning \& teaching: A New Zealand perspective. Retrieved August 14, 2012, from http://www.educationcounts.govt.nz/publications/schooling/109306

Boopsie Inc. (2012a). MU Library Mobile (Version 4.5.87) [Mobile application software] Retrieved October 2, 2012, from http://itunes.apple.com

Boopsie Inc. (2012b). UoA Library (Version 4.5.87) [Mobile application software] Retrieved October 2, 2012, from http://itunes.apple.com 
Bridges, L., Rempel, H. G., \& Griggs, K. (2010). Making the case for a fully mobile library web site: from floor maps to the catalog. Reference Services Review, 38(2), 309-320.

Canuel, R., Crichton, C., \& Savova, M. (2012). Tablets as Powerful Tools for University Research. [Case Study]. Library Technology Reports, 48(8), 35-41.

Careers NZ. (2013). Librarian: Entry requirements. Retrieved May 12, 2013, from http://www.careers.govt.nz/jobs/culture-heritage/librarian/how-to-enter-the-job

Chittaro, L. (2006). Visualizing information on mobile devices. Computer, 39(3), 40-45.

Creswell, J. W. (2014). Research design : qualitative, quantitative, and mixed methods approaches (4th ed.). Thousand Oaks: SAGE Publications.

Crown Fibre Holdings Limited. (2012). Getting excited about byod. Retrieved February 12, 2013, from http://www.crownfibre.govt.nz/2012/11/getting-excited-about-byod/

Dresselhaus, A., \& Shrode, F. (2012). Mobile technologies \& academics: Do students use mobile technologies in their academic lives and are librarians ready to meet this challenge? [Article]. Information Technology \& Libraries, 31(2), 82-101.

Geddes, S. (2004). M-learning in the C21st: Benefits for learners. Retrieved April 22, 2013, from http://pre2005.flexiblelearning.net.au/knowledgetree/edition06/html/pra simon geddes.h $\underline{\mathrm{tml}}$

Google. (n.d.). Discover android. Retrieved May 5, 2013, from http://www.android.com/about/

Google. (2012). Our mobile planet: Data set and country report: New Zealand Retrieved October 10, 2012, from http://www.thinkwithgoogle.com/mobileplanet/en/downloads/

Howie, J. E. (2013). An examination of home page design in New Zealand tertiary libraries. Master of Information Studies, Victoria University of Wellington, Wellington, N.Z. Retrieved from http://hdl.handle.net/10063/2673 
Johnson, L., Adam, S., \& Cummins, M. (2011). Technology outlook for New Zealand tertiary education 2011-2016: An NMC horizon report regional analysis. Austin, TX: The New Media Consortium.

King, K. P. (2001). Keeping pace with technology : Educational technology that transforms. Creskill, N.J.: Hampton Press.

Kroski, E. (2008). On the move with the mobile web: Libraries and mobile technologies. Library Technology Reports, 44(5), 5-9.

Laurillard, D. (2007). Pedagogical forms of mobile learning: Framing research questions. In N. Pachler (Ed.), Mobile learning: towards a research agenda (Occasional papers in work-based learning 1). Retrieved from Institute of Education, University of London website:

http://www.wlecentre.ac.uk/cms/files/occasionalpapers/mobilelearning pachler 2007.pdf.

Lee, R. (n.d.). Gesture cons. Retrieved September 12, 2012, from http://gesturecons.com/

Leedy, P. D., \& Ormrod, J. E. (2010). Practical research: Planning and design. (International edition; 9th ed.). Upper Saddle River, NJ: Pearson Education.

Library and Information Association of New Zealand Aotearoa. (n.d.). Professional registration. Retrieved May 16, 2013, from http://www.lianza.org.nz/registration

Lippincott, J. K. (2010). A mobile future for academic libraries. Reference Services Review, 38(2), 205213.

Liu, W., \& Cai, H. (2013). Embracing the shift to cloud computing: knowledge and skills for systems librarians. [Article]. OCLC Systems \& Services, 29(1), 22-29. doi: 1234283598348

MacCallum, K. S. (2011). Influences on the adoption of mobile technology by students and teachers. (Unpublished Doctoral thesis, Massey University Albany, 2011). Retrieved from http://mro.massey.ac.nz/handle/10179/3684. 
Massey University. (n.d.). Getting connected. Retrieved May 2, 2013, from

http://www.massey.ac.nz/massey/staffroom/national-shared-services/informationtechnology-services/networkcommunications/network/wireless-network/gettingconnected.cfm

Massey University Library. (2009). Library annual report for 2009. Retrieved May 4, 2013, from http://www.massey.ac.nz/massey/fms/Library/Documents/Publications/Annual\%20Reports Llibraryannualreport2009.pdf

Ministry of Education. (2010). Tertiary education strategy 2010-15. Retrieved September 27, 2012, from http://www.minedu.govt.nz/TertiaryEducationStrategy

National Library of New Zealand Te Puna Mātauranga o Aotearoa. (n.d.). Directory of New Zealand libraries. Retrieved May 20, 2012, from http://directory.natlib.govt.nz/library-symbolsweb/Home.html

Neo, E., \& Calvert, P. J. (2012). Facebook and the diffusion of innovation in New Zealand public libraries. [Article]. Journal of Librarianship \& Information Science, 44(4), 227-237. doi: $10.1177 / 0961000611435038$

New Zealand Qualifications Authority. (n.d.-a). About education organisations. Retrieved April 26, 2013, from http://www.nzqa.govt.nz/providers-partners/about-education-organisations/

New Zealand Qualifications Authority. (n.d.-b). Find education organisations. Retrieved April 26, 2013, from http://www.nzqa.govt.nz/providers/index.do

Oakley, S., \& Vaughan, J. (2007). Library and information agencies in the twenty-first century: Case studies: Higher education libraries. In S. Ferguson (Ed.), Libraries in the twenty-first century: Charting new directions in information services (pp. p.43 - 58). Wagga Wagga, NSW: Centre for Information Studies, Charles Sturt University.

Pacansky-Brock, M. (2013). Best practices for teaching with emerging technologies. New York, NY: Routledge. 
Paterson, L., \& Low, B. (2011). Student attitudes towards mobile library services for smartphones. Library Hi Tech, 29(3), 412-423. doi: 10.1108/07378831111174387

Rogers, E. M. (2003). Diffusion of innovations (5th ed.). New York: Free Press.

Roser, M. R. (2012). Influences on the professional development choices of library staff. (Unpublished MIS research project, Victoria University of Wellington, 2012). Retrieved from http://researcharchive.vuw.ac.nz/handle/10063/2341.

Saravani, S.-J., \& Haddow, G. (2011). The mobile library and staff preparedness: Exploring staff competencies using the unified theory of acceptance and use of technology model. Australian Academic \& Research Libraries, 42(3), 179-190.

Tech Terms. (2011). Mark up language. Retrieved October 4, 2013, from http://www.techterms.com/definition/markup language

The Council of New Zealand University Librarians. (2006). Best practice characteristics for developing information literacy in New Zealand universities: A guideline. Retrieved August 6, 2012, from http://www.universitiesnz.ac.nz/files/u2/CONZULInfoLiteracyBestPractice.pdf

United Nations Educational Scientific and Cultural Organization. (2012). Mobile learning for teachers: Global themes. Retrieved May 3, 2013, from http://unesdoc.unesco.org/images/0021/002164/216452E.pdf

University of Auckland. (n.d.). Wireless network. Retrieved May 2, 2013, from http://www.auckland.ac.nz/uoa/cs-wireless-network

W3C. (n.d.-a). Help for the W3C mobileOK checker: What is (are) this (these) failure message(s)? Retrieved May 21, 2013, from http://validator.w3.org/mobile/help.html\#errors

W3C. (n.d.-b). Style sheets in HTML documents. Retrieved May 26, 2013, from http://www.w3.org/TR/REC-html40/present/styles.html 
W3C. (n.d.-c). Validation as a debugging tool. Retrieved May 26, 2013, from http://validator.w3.org/docs/why.html

W3C. (n.d.-d). What do the severity levels represent? Retrieved May 21, 2013, from http://validator.w3.org/mobile/help.html\#severity

Wanganui Collegiate School. (n.d.). St Georges School: Years 7 and 8. Retrieved February 12, 2013, from http://www.collegiate.school.nz/st-georges/years-7-and-8-/104/137/

Wiebrands, M. (2012). The coming paradigm shift in computing interfaces and how academic libraries need to adapt. Paper presented at the Proceedings of the 2012 IATUL Conferences, 4-7 June 2012. Retrieved from Purdue University Purdue e-Pubs:

http://docs.lib.purdue.edu/cgi/viewcontent.cgi?article=1099\&context=iatul 


\section{APPENDIX 1: PARTICIPANT INFORMATION SHEET - EMAIL TO}

\section{LIBRARY MANAGERS}

Tēnā koe,

As part of the completion of the Master of Information Studies degree, I am undertaking a research project to investigate the adoption and use of mobile technologies within Aotearoa New Zealand's higher education libraries. The extent to which library staff are supported and encouraged to adapt to a less traditional model of service will be explored, as well as library staff attitude, perception and experience in using mobile technology. Further, it is anticipated this research will provide insight into the professional development needs of library staff and/or the organisational design of the higher education library within Aotearoa New Zealand.

I invite technical and teaching library staff, and library IT staff from the following higher education libraries to participate:

\section{University}

- Auckland University of Technology

- Lincoln University

- Massey University

- University of Auckland

- University of Canterbury

- University of Waikato

- University of Otago

- Victoria University of Wellington

\section{Institute of Technology / Polytechnic}

- Aoraki Polytechnic

- Bay of Plenty Polytechnic

- Christchurch Polytechnic Institute of Technology

- Easter Institute of Technology / Tairawhiti Polytechnic

- Manukau Institute of Technology

- Nelson Marlborough Institute of Technology

- Northland Polytechnic / NorthTech

- Open Polytechnic

- Otago Polytechnic

- Southern Institute of Technology

- Tai Poutini Polytechnic

- Unitec Institute of Technology

- Universal College of Learning

- Waiariki Institute of Technology

- Waikato Institute of Technology

- Wellington Institute of Technology

- Western Institute of Technology at Taranaki

- Whitireia Community Polytechnic

\section{Wānanga}

- Te Wānanga o Aotearoa 
- Te Wānanga o Raukawa

- Te Whare Wānanga o Awanuirangi

This survey will take approximately 15-20 minutes to complete and all data collected will be kept securely in a password protected file. The survey will be valid for one month from Monday 9 September 2013 to Sunday 6 October 2013. A reminder email will be sent after a fortnight, on Monday 23 September 2013. Victoria University of Wellington requires, and has granted, approval from the School's Human Ethics Committee. To participate in this research, please click the link below:

http://vuw.qualtrics.com/SE/?SID=SV dd284BUTChAvZ09

To assist with survey participation, it would be greatly appreciated if you would please pass this email on to staff within your library.

If you have any questions, or would like to receive further information about this research, please contact me at maniaptrac@myvuw.ac.nz or you may contact my supervisor, Dr. Brenda Chawner, Information Studies Programme Director at brenda.chawner@vuw.ac.nz or telephone (04) 4635780.

Ngā mihi

Tracy Maniapoto 


\section{APPENDIX 2: PARTICIPANT INFORMATION SHEET - EMAIL TO}

\section{LISTSERVS}

(Apologies for cross posting)

E ngā iwi o te motu, tēnā koutou katoa,

As part of the completion of the Master of Information Studies degree, I am undertaking a research project to investigate the adoption and use of mobile technologies within Aotearoa New Zealand's higher education libraries. The extent to which library staff are supported and encouraged to adapt to a less traditional model of service will be explored, as well as library staff attitude, perception and experience in using mobile technology.

I invite technical library staff, teaching library staff, and library IT staff from the following higher education libraries to participate:

\section{University}

- Auckland University of Technology

- Lincoln University

- Massey University

- University of Auckland

- University of Canterbury

- University of Waikato

- University of Otago

- Victoria University of Wellington

\section{Institute of Technology / Polytechnic}

- Aoraki Polytechnic

- Bay of Plenty Polytechnic

- Christchurch Polytechnic Institute of Technology

- Easter Institute of Technology / Tairawhiti Polytechnic

- Manukau Institute of Technology

- Nelson Marlborough Institute of Technology

- Northland Polytechnic / NorthTech

- Open Polytechnic

- Otago Polytechnic

- Southern Institute of Technology

- Tai Poutini Polytechnic

- Unitec Institute of Technology

- Universal College of Learning

- Waiariki Institute of Technology

- Waikato Institute of Technology

- Wellington Institute of Technology

- Western Institute of Technology at Taranaki

- Whitireia Community Polytechnic 


\section{Wānanga}

- Te Wānanga o Aotearoa

- Te Wānanga o Raukawa

- Te Whare Wānanga o Awanuirangi

This survey will take approximately 15-20 minutes to complete and all data collected will be kept securely in a password protected file. The survey will be valid for one month from Monday 9 September 2013 to Sunday 6 October 2013. Victoria University of Wellington requires, and has granted, approval from the School's Human Ethics Committee. To participate in this research, please click the link below:

http://vuw.qualtrics.com/SE/?SID=SV dd284BUTChAvZ09

If you have any questions, or would like to receive further information about this research, please contact me at maniaptrac@myvuw.ac.nz or you may contact my supervisor, Dr. Brenda Chawner, Information Studies Programme Director at brenda.chawner@vuw.ac.nz or telephone (04) 4635780.

Ngā mihi

Tracy Maniapoto 


\section{APPENDIX 3: PARTICIPANT INFORMATION SHEET - FIRST PAGE}

\section{OF QUALTRICS SURVEY}

Research Project Title: Is there an app for that? An exploratory study into the use of mobile technologies and mLearning within Aotearoa New Zealand's higher education libraries.

Researcher: Tracy Maniapoto, School of Information Management, Victoria University of Wellington

As part of the completion of my Master of Information Studies degree at Victoria University of Wellington, this research is designed to investigate the adoption/non-adoption of mobile technologies within Aotearoa New Zealand's higher education libraries, and provide an opportunity to comparatively examine their use of innovative technologies in serving the needs of their community. Victoria University of Wellington requires, and has granted, approval from the School's Human Ethics Committee.

I am inviting technical and teaching library staff, and library IT staff to participate in this research by completing an online survey. Participants must be employed by, or work for, a higher education library attached to one of the 31 named Aotearoa New Zealand tertiary education providers below:

\section{University}

- Auckland University of Technology

- Lincoln University

- Massey University

- University of Auckland

- University of Canterbury

- University of Waikato

- University of Otago

- Victoria University of Wellington

\section{Institute of Technology / Polytechnic}

- Aoraki Polytechnic

- Bay of Plenty Polytechnic

- Christchurch Polytechnic Institute of Technology

- Easter Institute of Technology / Tairawhiti Polytechnic

- Manukau Institute of Technology

- Nelson Marlborough Institute of Technology

- Northland Polytechnic / NorthTech

- Open Polytechnic

- Otago Polytechnic

- Southern Institute of Technology

- Tai Poutini Polytechnic

- Unitec Institute of Technology

- Universal College of Learning

- Waiariki Institute of Technology

- Waikato Institute of Technology

- Wellington Institute of Technology

- Western Institute of Technology at Taranaki

- Whitireia Community Polytechnic 


\section{Wānanga}

- Te Wānanga o Aotearoa

- Te Wānanga o Raukawa

- Te Whare Wānanga o Awanuirangi

Participation in the online survey is voluntary and will take 15-20 minutes to complete. Neither you, nor your workplace, will be identified in any written report produced as a result of this research, including possible publication in academic conferences and journals. All material collected will be kept confidential, and will be viewed only by myself and my supervisor, Dr. Brenda Chawner, Information Studies Programme Director, Victoria University of Wellington. To thank you for your participation, I am offering you the chance to enter a draw to win a $\$ 50.00$ gift card from MightyApe (www.mightyape.co.nz). Details for the draw will be included on the last page of the survey.

By submitting the survey, you are agreeing to participate in this research. The survey has been designed to be anonymous. Information you provide will be combined with other responses from library staff around Aotearoa New Zealand. Any information that you provide that could reveal who you are or where you work will be anonymised to ensure privacy.

The research project will be submitted for marking to the School of Information Management, and subsequently deposited in the University Library, approximately December 2013. As this survey is anonymous, no information identifying individuals or their employers will be included in the final report. If you provide an email address to be eligible for the prize draw, it will be removed from the data before they are analysed. All data collected from participants will be destroyed within $\mathbf{2}$ (two) years after the completion of the project.

If you have any questions or would like to receive further information about the project, please contact me at maniaptrac@myvuw.ac.nz or you may contact my supervisor Dr. Brenda Chawner, Information Studies Programme Director at Brenda.chawner@vuw.ac.nz or telephone (04) 463-5780.

Tracy Maniapoto 


\section{APPENDIX 4: PARTICIPANT QUESTIONS FOR ONLINE SURVEY}

\section{USING QUALTRICS}

PART A: Please confirm your details to proceed with the online survey:

1. Are you employed by, or work for, a higher education library attached to one of the 29 named tertiary education providers as listed below:

\section{University}

- Auckland University of Technology

- Lincoln University

- Massey University

- University of Auckland

- University of Canterbury

- University of Waikato

- University of Otago

- Victoria University of Wellington

\section{Institute of Technology / Polytechnic}

- Aoraki Polytechnic

- Bay of Plenty Polytechnic

- Christchurch Polytechnic Institute of Technology

- Easter Institute of Technology / Tairawhiti Polytechnic

- Manukau Institute of Technology

- Nelson Marlborough Institute of Technology

- Northland Polytechnic / NorthTech

- Open Polytechnic

- Otago Polytechnic

- Southern Institute of Technology

- Tai Poutini Polytechnic

- Unitec Institute of Technology

- Universal College of Learning

- Waiariki Institute of Technology

- Waikato Institute of Technology

- Wellington Institute of Technology

- Western Institute of Technology at Taranaki

- Whitireia Community Polytechnic

\section{Wānanga}

- Te Wānanga o Aotearoa

- Te Wānanga o Raukawa

- Te Whare Wānanga o Awanuirangi 
2. Please indicate your main role within the library environment (select one only):

a. I provide information literacy support in a face-to-face, online or blended learning environment

b. I provide technical support for the library's content management systems e.g. mobile web optimization/integration

c. I provide ICT support for staff and students within the library e.g. Wi-Fi connectivity

d. None of the above

Response: (single response) - If participant selects a), b) or c), then go to Part B. If participant selects $d$ ), end survey

For the purpose of Parts B and C, mobile technology relates to the use of a mobile device, such as a smartphone or tablet, which facilitates access to and sharing of information anywhere, anytime.

\section{PART B:}

Please state the level to which you agree or disagree with the following statements related to your perceptions of mobile technology:

I enjoy using mobile technology

I have used a mobile app

I'm not sure of the difference between a mobile app, and mobile web optimisation

I prefer to learn about mobile technology on my own

I prefer someone shows me how to use mobile technology

I am more likely to try mobile technology if recommended by a friend or family member

\section{PART C:}

Please state the level to which you agree or disagree with the following statements related to mobile technology use within your library:

My workplace adopted mobile technology before I did

I am required to learn about mobile technology as part of my work

I am required to use mobile technology as part of my work

I would like more opportunities to use mobile technologies at work

My workplace supports the use of mobile technologies

I support others within the workplace to use mobile technologies

The use of mobile technologies is compatible with my library's culture and values

The use of mobile technologies would meet the needs of our library's

customers better

Part D: The following questions focus on the use of a mobile app within the library environment:

1. To your knowledge, does your library provide a mobile app to access library resources?

a. If YES - go to Part D: Q2 

b. If NO - go to Part D: Q3
c. If I DON'T KNOW - go to Part D: Q4

2. Please indicate the ways in which you promote your library's mobile app (select as many as required):
a. I don't promote the library app
b. Information Literacy Instruction - Face-to-face
c. Information Literacy Instruction - Online/Blended e.g. Moodle, Blackboard
d. Library Website
e. Library Blog
f. Library Social Media e.g. Twitter, Facebook
g. Research Consultations with Academic Staff
h. Library Marketing (please specify):
i. Other (please specify):
j. GO TO PART E

3. What services would you expect to see available on a library mobile app (select as many as required):
a. Library Catalogue
b. Library Hours of Operation
c. Library Contact Information
d. Library Workshops
e. Ask a Librarian / Ask a Question
f. Managing Your Library Account e.g.: request or renew a library item
g. Library blog
h. Book a study room
i. Other (please state):
j. GO TO Q4

4. How might you promote a library mobile app to staff and students within the library? GO TO Q5

5. Why do you think your library decided not to adopt a library mobile app?

Part E: The following questions focus on 'mobile web optimisation', that is, the way your library's online environment is displayed on a mobile device, such as a tablet or smartphone, when using a mobile device's internet browser:

1. To your knowledge, does your library's website provide a mobile web interface that permits easy access to library resources on a tablet or smartphone?
a. If YES - go to Part E: Q2 \& Q3
b. If NO - go to Part E: Q4
c. If I DON'T KNOW - go to Part E: Q4

2. Please indicate which of your library webpages are optimised for use on a mobile device (select as many as required):
a. I'm not sure / I don't know
b. Library Homepage
c. Library Catalogue 

d. Library Databases
e. Learning Objects / Online Video Tutorials
f. Other (please specify):
g. GO TO Q3

3. Please indicate the ways in which you promote your library's mobile web services (select as many as required):
a. I don't promote the library's mobile web
b. Information Literacy Instruction - Face-to-face
c. Information Literacy Instruction - Online/Blended e.g. Moodle, Blackboard
d. Library Website
e. Library Blog
f. Library Social Media e.g. Twitter, Facebook
g. Research Consultations with Academic Staff
h. Library Marketing (please specify):
i. Other (please specify):
j. GO TO PART F

4. What library services would you expect to see optimised for the mobile web (select as many as required):
a. Library Homepage
b. Library Catalogue
c. Library Databases
d. Learning Objects / Online Video Tutorials
e. Other (please specify):
f. GO TO Q5

5. How might you promote your library's mobile web to staff and students within the library? GO TO Q6

6. Why do you think your library decided not to adopt mobile web optimisation?

PART F: Please provide the following demographic information:

1. Gender
a. Female
b. Male
c. Prefer not to answer

2. Age
a. Under 20
b. $20-29$
c. $30-39$
d. $40-49$
e. Over 50
f. Prefer not to answer

3. Do you have any other comments regarding this survey?

FEEDBACK: A summary of research results will be sent to each library manager with a request to distribute the summary to all staff. 
DRAW: Would you like to enter the draw to win a $\$ 50.00$ gift voucher from Mighty Ape (www.mightyape.co.nz)?

a. Yes - please provide your first name, surname and contact email address. Thank you for participating in this online survey.

b. No - thank you for participating in this online survey. 
